\title{
Effects of uncertainties in the thermodynamic properties of aerosol components in an air quality model - Part 1: Treatment of inorganic electrolytes and organic compounds in the condensed phase
}

\author{
S. L. Clegg ${ }^{1}$, M. J. Kleeman ${ }^{2}$, R. J. Griffin ${ }^{3}$, and J. H. Seinfeld ${ }^{4}$ \\ ${ }^{1}$ School of Environmental Sciences, University of East Anglia, Norwich NR4 7TJ, UK \\ ${ }^{2}$ Department of Civil and Environmental Engineering, University of California, Davis CA 95616, USA \\ ${ }^{3}$ Institute for the Study of Earth, Oceans and Space, and Department of Earth Sciences, University of New Hampshire, \\ Durham, NH 03824, USA \\ ${ }^{4}$ Department of Chemical Engineering, California Institute of Technology, Pasadena, CA 91125, USA
}

Received: 1 June 2007 - Published in Atmos. Chem. Phys. Discuss.: 26 July 2007

Revised: 14 December 2007 - Accepted: 15 January 2008 - Published: 27 February 2008

\begin{abstract}
Air quality models that generate the concentrations of semi-volatile and other condensable organic compounds using an explicit reaction mechanism require estimates of the physical and thermodynamic properties of the compounds that affect gas/aerosol partitioning: vapour pressure (as a subcooled liquid), and activity coefficients in the aerosol phase. The model of Griffin, Kleeman and coworkers (e.g., Griffin et al., 2003; Kleeman et al., 1999) assumes that aerosol particles consist of an aqueous phase, containing inorganic electrolytes and soluble organic compounds, and a hydrophobic phase containing mainly primary hydrocarbon material. Thirty eight semi-volatile reaction products are grouped into ten surrogate species which partition between the gas phase and both phases in the aerosol. Activity coefficients of the organic compounds are calculated using UNIFAC. In a companion paper (Clegg et al., 2008) we examine the likely uncertainties in the vapour pressures of the semi-volatile compounds and their effects on partitioning over a range of atmospheric relative humidities. In this work a simulation for the South Coast Air Basin surrounding Los Angeles, using lower vapour pressures of the semi-volatile surrogate compounds consistent with estimated uncertainties in the boiling points on which they are based, yields a doubling of the predicted 24-h average secondary organic aerosol concentrations. The dependency of organic compound partitioning on the treatment of inorganic electrolytes in the air quality model, and the performance of this component of the model, are determined by analysing the results of a trajec-
\end{abstract}

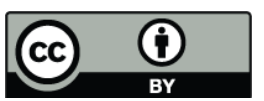

Correspondence to: S. L. Clegg

(s.clegg@uea.ac.uk) tory calculation using an extended version of the Aerosol Inorganics Model of Wexler and Clegg (2002). Simplifications are identified where substantial efficiency gains can be made, principally: the omission of dissociation of the organic acid surrogates; restriction of aerosol organic compounds to one of the two phases (aqueous or hydrophobic) where equilibrium calculations suggest partitioning strongly in either direction; a single calculation of activity coefficients of the organic compounds for simulations where they are determined by the presence of one component at high concentration in either phase (i.e., water in the aqueous phase, or a hydrocarbon surrogate compound P8 in the hydrophobic phase) and are therefore almost invariant. The implications of the results for the development of aerosol models are discussed.

\section{Introduction}

Atmospheric models of the inorganic components of aerosols, principally ammonium, sulphate, sea salt, components of wind blown dust, and nitrate, are relatively well established (e.g., Zhang et al., 2000; Jacobson, 1997; Nenes et al., 1998; Wexler and Clegg, 2002). The models are based upon extensive laboratory data for physical and thermodynamic properties of the relatively small number of components present, equilibrium constants for the formation of solids and gases, and activity coefficient models of varying levels of complexity and accuracy which are used to calculate aerosol water uptake and the activities of solute species needed to estimate gas/aerosol partitioning.

Published by Copernicus Publications on behalf of the European Geosciences Union. 


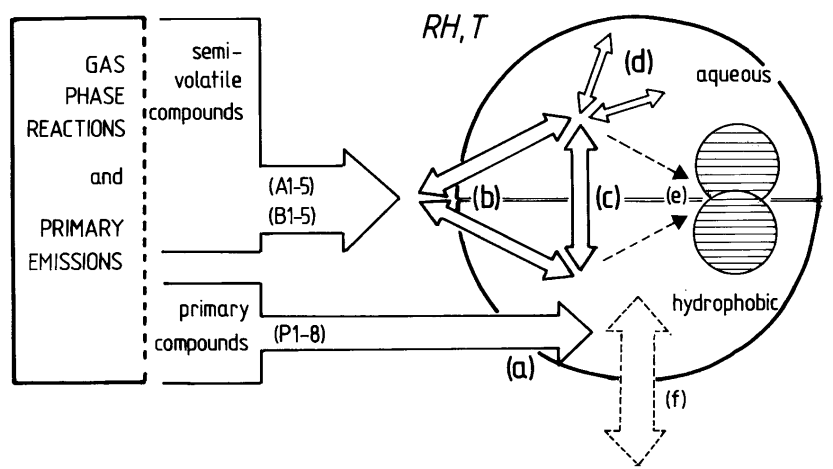

Fig. 1. Production and gas to aerosol partitioning of organic compounds, based upon the scheme proposed by Pun et al. (2002). The aerosol particle on the right hand side contains an upper aqueous portion and lower hydrophobic (organic) phase. Gas phase reactions and emissions on the left hand side produce solid material or involatile products (grouped into primary compounds P1 to P8 in the UCD-CACM model) which are assigned in step (a) directly to the hydrophobic aerosol phase. Partitioning into the gas phase is possible for at least some of these compounds, step (f), but is not included in the UCD-CACM model. Semi-volatile compounds produced in the gas phase are grouped into a smaller number of surrogate species (38 compounds are assigned to surrogates A1 to A5, and $\mathrm{B} 1$ to $\mathrm{B} 5$, in the UCD-CACM model). These are allowed to partition between the gas phase and both aqueous and hydrophobic phases in the aerosol, in step (b). Equilibrium between the two aerosol phases, step (c), is calculated. Surrogates containing - $\mathrm{COOH}$ groups can dissociate in the aqueous phase, step (d). Reactions, step (e), in the aerosol phases may sequester semi-volatile compounds in the condensed phase. Such reactions are not included explicitly in the UCD-CACM model.

The composition and properties of the organic portion of aerosols, particularly secondary compounds formed from gas phase reactions, are much less well understood (Kanakidou et al., 2005). A significant fraction of the organic aerosol material remains uncharacterised, and the thermodynamic properties of the secondary compounds that have been identified (e.g., Yu et al., 1999; Jaoui et al., 2005) have generally not been measured. Evidence suggests that oligomerisation and other aerosol phase reactions can be important, and enhance the formation of secondary organic aerosol (SOA) material (Jang et al., 2003; Kalberer et al., 2006). The most common atmospheric codes treat the organic components of aerosols, including SOA formation, using a lumped two component approach developed to represent the results of chamber experiments (Odum et al., 1996; Griffin et al., 1999). For example, in the Community Multiscale Air Quality (CMAQ) model of U.S. EPA, anthropogenic and biogenic SOA-forming material are each represented by this two component approach and partition into the organic fraction of the aerosol which also contains primary organic material (Yu et al., 2007). There are no interactions with the inorganic components of the aerosol. An alternative approach is an explicit model in which the formation of condensable and semi-volatile organic compounds are first calculated using a gas phase kinetic model (e.g., Jenkin et al., 2003; Griffin et al., 2002). The reaction products can then be grouped into a smaller number of surrogates in order to make gas/aerosol partitioning calculations efficient (e.g., Bian and Bowman, 2005; Griffin et al., 2003). The key thermodynamic properties of these compounds or surrogates - particularly their vapour pressures and activities in the aerosol liquid phase(s) - can be estimated using structure-based methods. We evaluate the uncertainties associated with the vapour pressures of the surrogate compounds in a second study (Clegg et al., 2008), hereafter referred to as Paper 2. This work focuses on the impact on calculated gas/aerosol partitioning of uncertainties in some of the key elements of the thermodynamic treatment of both inorganic and organic aerosol compounds, including: activity coefficients, aerosol water content, solids formation, dissociation equilibria, and the treatment of groups of organic compounds using a reduced number of surrogate species. A current state-of-the-science air quality model (Kleeman et al., 1997; Kleeman and Cass, 1998; Kleeman et al., 1999) is used in the analysis in order to understand the practical effects of errors and uncertainties in atmospheric simulations.

The elements of a generalised scheme for including the organic elements of aerosols in air quality and other atmospheric models are shown in Fig. 1, based on that described by Pun et al. (2002). Primary emissions of particles and condensable organic vapours are represented on the lower left hand side of the figure, and reactions producing semi-volatile products above. The large number of compounds is reduced to a smaller number of surrogates for the gas/particle partitioning calculation. It is possible that multiple organic phases could exist in the aerosol and that each of the surrogate compounds would be present in all of them. This would create a difficult and time consuming optimisation problem. The simplest approach is shown in Fig. 1: the aerosol has an aqueous phase dominated by inorganic ions, and a hydrophobic phase containing the primary compounds which have a mainly hydrocarbon character and which are insoluble in water.

In steps (a) and (b) in Fig. 1 the partitioning of the primary and semi-volatile surrogate compounds between gas and aerosol phases is calculated for one or more aerosol size classes. This process is driven by the (subcooled) liquid vapour pressures of the surrogate compounds and the associated enthalpies of vaporisation, and the activities in the aqueous and hydrophobic phases. These activities, and the amounts of liquid water (mainly controlled by inorganic ions) and hydrophobic compounds present, determine their partitioning between the two liquid phases (step c). The amounts of some compounds can be enhanced in the aqueous phase by step (d), dissociation, which is determined from the dissociation constants and the activities of the undissociated organic molecule, $\mathrm{H}_{(\mathrm{aq})}^{+}$and the organic anions. Condensed phase oligomerisation and other reactions, which are represented by step (e), may form larger molecules of low 
volatility, effectively sequestering some of the semi-volatile surrogates in the aerosol until wet or dry deposition removes them from the atmosphere. There is evidence that high molecular weight hydrocarbons and other primary emissions are able to partition between gas and aerosol phases (Fraser et al., 1997, 1998), step (f), which is included here for completeness.

The treatment illustrated in Fig. 1 is conceptually simple, but still requires more information than is currently available to quantify properties and define each step of the gas/aerosol partitioning process accurately. In this study and in Paper 2 we examine uncertainties in predictive methods that affect gas/aerosol partitioning of semi-volatile compounds (the net effect of steps (b), (c) and (d) in Fig. 1). This work focuses on the calculation of activity coefficients, the effects of the inorganic thermodynamic treatment on the partitioning of semivolatile compounds, the selection of surrogate compounds and the assignment and estimation of their properties.

In order to relate these studies to their practical effects in air quality calculations, we use the model of Griffin, Kleeman and co-workers, hereafter referred to as the UCDCACM model (where CACM stands for the Caltech Atmospheric Chemistry Mechanism) as an example. The model conforms to the general scheme shown in the Fig. 1, but with some simplifications. These are, first, that the primary compounds are assumed to be involatile and are assigned directly to the hydrophobic aerosol phase in step (a). Second, that steps (e) and (f) are omitted. The 3-D Lagrangian version of the UCD-CACM air quality model was used to simulate a series of 24 air parcel trajectories ending at two locations in Southern California on successive hours of the day on 9 September 1993. The main location studied was Claremont, California, which was heavily influenced by anthropogenic emissions from urban Los Angeles during that period. Output from the UCD-CACM model for gas/aerosol partitioning, as total amounts of each species per $\mathrm{m}^{3}$ at each time interval, was used as input to a flexible code (Clegg, 2004) incorporating the AIM model of Wexler and Clegg (2002), and able to calculate the state of systems corresponding to the schematic in Fig. 1 (excluding the reactions in step e). In this work we refer to this extended model simply as AIM. This model was developed as a benchmark code of high accuracy, and is therefore suitable as a reference against which the simplified (but much faster) thermodynamic schemes used in atmospheric models such as the UCD-CACM code can be compared. We examine the results of the two models in some detail, for both inorganic and organic components, in order to fully understand the differences between them and their effects in air quality simulations. Their basic features are summarised in Table 5 in Appendix B.

Gas/aerosol partitioning in the UCD-CACM model is calculated dynamically, whereas AIM determines the equilibrium state of an aerosol system. The UCD-CACM model and AIM results are therefore compared for situations where the UCD-CACM result is close to equilibrium, or with equilib- rium properties such as activity coefficients and partial pressures calculated directly using the UCD-CACM model. This ensures consistency. The results are relevant, first, to the general development of atmospheric aerosol models based upon an explicit chemistry and corresponding to Fig. 1, highlighting particular areas in which a better quantitative understanding of the physical chemistry is needed. Second, they identify elements of the UCD-CACM model on which future work is likely to focus.

In the section below we describe the thermodynamic models used and the chemical system treated, and summarise the calculation of solvent and solute activities and key uncertainties.

\section{The models}

The UCD-CACM source-oriented air quality trajectory model is a reactive photochemical transport model that describes pollutant emissions, transport, chemical transformation, and deposition (Kleeman et al., 1997; Kleeman and Cass, 1998; Kleeman et al., 1999). The model includes all of the atmospheric operators used in the full 3-D UCD/CIT airshed model (Kleeman and Cass, 2001; Held et al., 2004; Ying et al., 2007) but the Lagrangian trajectory framework is more computationally efficient than the Eulerian approach. Particles emitted from different sources are tracked separately through the full atmospheric simulation to capture the heterogeneous nature of real atmospheric particulate matter. The aerosol is externally mixed. Gas-phase precursors can also be tracked through the photochemical mechanism to identify source-contributions to secondary reaction products (Mysliwiec and Kleeman, 2002; Ying and Kleeman, 2007; Kleeman et al., 2007). The trajectory framework is not capable of representing vertical wind shear or horizontal turbulent diffusion.

The Caltech Atmospheric Chemistry Mechanism (CACM) is used to describe the photochemical reactions in the atmosphere including the formation of semi-volatile products leading to the production of secondary organic aerosol. The modelled system consists of 139 gas-phase species participating in 349 chemical reactions, and inorganic ions, gases, and solids (Griffin et al., 2002). For the purpose of calculating gas/aerosol partitioning, the semi-volatile species generated by chemical reaction, and capable of forming SOA, are combined into a set of 10 surrogate species A1-5 and B1-5 (Griffin et al., 2005). There are, in addition, 8 primary organic hydrocarbons (P1-8) which are assumed to exist only in the aerosol phase.

Aerosol particles in the UCD-CACM model can consist of 2 liquid phases (see Fig. 1): first, an aqueous phase containing water, inorganic ions, and some fraction of the SOA surrogates and their dissociation products; second, a hydrophobic phase containing the primary hydrocarbons and the SOA surrogates (non-dissociated molecules only) which equilibrate between the two phases. Inorganic solids are able to 
form, based upon their known deliquescence relative humidities and equilibrium constants. No organic solids form, even at low relative humidity ( $\mathrm{RH})$, and the hydrophobic aerosol phase is assumed always to exist as a subcooled liquid. This assumption is justified by the fact that the very large numbers of organic compounds likely to be present in real atmospheric aerosols will greatly depress the temperature at which solids will form (e.g., Marcolli et al., 2004).

Aerosols are represented by 15 size bins, with compositions determined by the original source and the dynamically driven partitioning of water, $\mathrm{NH}_{3}, \mathrm{HNO}_{3}, \mathrm{HCl}$ and other trace gases, and chemical reactions occurring in both the aerosol and gas phases (Kleeman et al., 1997; Kleeman et al., 2007). Bins 1 to 5, corresponding to particles with aerodynamic diameter smaller than $0.1 \mu \mathrm{m}$, are not considered in the comparisons here, in part because the focus of this study is on effects on the total amounts of organic compounds in the aerosol phase - most of which occurs for particles larger than $0.1 \mu \mathrm{m}$, and also because the reference AIM model (Clegg, 2004; Wexler and Clegg, 2002) does not include the Kelvin effect which has an important effect on partitioning for particles below this size.

The AIM model calculates the thermodynamic equilibrium state of gas/aerosol systems containing known total amounts of material per $\mathrm{m}^{3}$ (Wexler and Clegg, 2002). A single bulk aerosol phase, which is internally mixed, is assumed. The models have recently been extended to include organic compounds with user-specified properties, ammonia and water dissociation, and a hydrophobic liquid aerosol phase (Clegg, 2004). Organic compounds are able to partition between the gas phase and both fractions of the aerosol or, if required, their occurrence and partitioning can be limited to phases chosen by the user. The model is thus able to emulate the thermodynamic treatment of gas/aerosol partitioning in atmospheric codes of a range of complexity, including both the UCD-CACM model and, for example, the treatment of SOA formation in CMAQ (Yu et al., 2007).

The gas/aerosol partitioning of water-soluble organic semi-volatile compounds links to the thermodynamics of the inorganic portion of the aerosol mainly via the amount of aerosol water, dissociation to $\mathrm{H}_{(\mathrm{aq})}^{+}$and organic anions, and interactions between inorganic ions and uncharged organic molecules that lead to changes in the activity coefficients. Variations between models will be most apparent at low relative humidity both because differences between calculated water activity/concentration relationships of the solutes tend to be greatest at low RH, and especially because models may not predict the same amounts of inorganic solids to form causing large differences in predicted aerosol water content. The treatment of the activity coefficients of $\mathrm{H}_{(\mathrm{aq})}^{+}$, and organic anions can also differ, thus affecting the calculated degrees of dissociation of the organic compounds.

The chemical components of the atmospheric system, and the main elements of both models that affect calculated gas aerosol partitioning, are described below.

\subsection{Chemical system}

The inorganic ions in the aerosol system are $\mathrm{H}^{+}$, $\mathrm{NH}_{4}^{+}, \mathrm{Na}^{+}, \mathrm{SO}_{4}^{2-}, \mathrm{NO}_{3}^{-}$and $\mathrm{Cl}^{-}$. The gases $\mathrm{NH}_{3}$, $\mathrm{HNO}_{3}$ and $\mathrm{HCl}$ are also included, as are the solids $\left(\mathrm{NH}_{4}\right)_{2} \mathrm{SO}_{4(\mathrm{~s})},\left(\mathrm{NH}_{4}\right)_{3} \mathrm{H}\left(\mathrm{SO}_{4}\right)_{2(\mathrm{~s})}$ (letovicite), $\mathrm{NH}_{4} \mathrm{HSO}_{4(\mathrm{~s})}$, $\mathrm{NH}_{4} \mathrm{NO}_{3(\mathrm{~s})}$ and $\mathrm{NaCl}_{(\mathrm{s})}$. All these species are included in both models. Further solids $2 \mathrm{NH}_{4} \mathrm{NO}_{3} .\left(\mathrm{NH}_{4}\right)_{2} \mathrm{SO}_{4(\mathrm{~s})}$, $3 \mathrm{NH}_{4} \mathrm{NO}_{3} \cdot\left(\mathrm{NH}_{4}\right)_{2} \mathrm{SO}_{4(\mathrm{~s})}$, and $\mathrm{NH}_{4} \mathrm{HSO}_{4} \cdot \mathrm{NH}_{4} \mathrm{NO}_{3(\mathrm{~s})}$ are treated by the AIM model only. The 8 primary hydrocarbons (P1-8) and 10 semi-volatile surrogate species (A1-5, and B15), which are included in both models, are described in Appendix A.

The semi-volatile species present in the aerosols are assumed to partition at equilibrium between the two liquid phases at all times, according to:

$x_{i(\mathrm{aq})} f_{i(\mathrm{aq})}=x_{i(\mathrm{org})} f_{i(\mathrm{org})}$

where subscript (aq) indicates the mole fraction $(x)$ or mole fraction activity coefficient $(f)$ of each species $i$ in the aqueous phase, and subscript (org) the same quantities in the hydrophobic liquid phase. The activity coefficient $f$ is relative to a pure liquid reference state (i.e., $f_{i}=1.0$ when $x_{i}=1.0$ ). The equilibrium partial pressures $\left(p_{i}\right)$ of the semi-volatile organic surrogates over the liquid aerosol, which drive their mass transfer between vapour and aerosol phases, are calculated according to:

$p_{i}=x_{i} f_{i} p_{i}^{o}$

where $p_{i}^{o}$ is the subcooled liquid vapour pressure of component $i$, and $x_{i}$ is the mole fraction of organic compound $i$ in the aqueous and/or hydrophobic phases. The dissociation of the organic acids and diacids $\mathrm{H}_{2} \mathrm{X}$ is governed by the following equations:

$$
\begin{aligned}
& K_{d 1}=m \mathrm{H}^{+} \gamma \mathrm{H}^{+} m \mathrm{HX}^{-} \gamma \mathrm{HX}^{-} /\left(m \mathrm{H}_{2} \mathrm{X} \gamma \mathrm{H}_{2} \mathrm{X}\right) \\
& K_{d 2}=m \mathrm{H}^{+} \gamma \mathrm{H}^{+} m \mathrm{X}^{2-} \gamma \mathrm{X}^{2-} /\left(m \mathrm{HX}^{-} \gamma \mathrm{HX}^{-}\right)
\end{aligned}
$$

where $K_{d 1}\left(\mathrm{~mol} \mathrm{~kg}^{-1}\right)$ and $K_{d 2}\left(\mathrm{~mol} \mathrm{~kg}^{-1}\right)$ are the first and second stepwise dissociation constants, respectively, prefix $m$ denotes molality, and $\gamma_{i}$ is the molality based activity coefficient of the indicated species. (See Robinson and Stokes, 1965 , for relationships between activity coefficients on the different concentration scales.) The treatment of singly dissociating acid $\mathrm{HY}$ is analogous to that above but based on the equation $K_{d}=m \mathrm{H}^{+} \gamma \mathrm{H}^{+} m \mathrm{Y}^{-} \gamma \mathrm{Y}^{-} /(m \mathrm{HY} \gamma \mathrm{HY})$. The dissociating organic surrogate species are B1, B2, A1, A2 and A4, and their dissociation constants are listed in Appendix A. The calculation of the activity coefficients used in Eqs. (3a, b) by both models is discussed in the section below.

The UCD-CACM model calculates the formation of inorganic solids by minimising the Gibbs free energy of the inorganic species. Thermodynamic information for the minimization calculation is taken from Wexler and Seinfeld 
(1991). In the AIM model, the equilibrium constants listed in Table 2 of Clegg et al. (1998a) are used to obtain Gibbs energies of formation of the solids and gas phase species, and no independent knowledge of the deliquescence relative humidities of the individual solid phases is required. The Henry's law constants of the gases $\mathrm{HNO}_{3}, \mathrm{NH}_{3}$, and $\mathrm{HCl}$ that govern the equilibrium of these species between aqueous and gas phases are well established (e.g., Carslaw et al., 1995; Clegg et al., 1998a, b), and the effects of any differences in the values of these constants used in the two models are likely to be small.

In the UCD-CACM model each aerosol size bin exchanges water dynamically with the surrounding gas-phase (equilibrium is not assumed). The effective water activity above each particle surface is calculated according to the method described by Pruppacher and Klett (1978) to account for modification of the surface temperature during rapid condensation or evaporation of water vapour. Thus the larger aerosol size bins and gas phase may not always be close to equilibrium with respect to water. The water content of each size bin is also not permitted to become zero, and a residual amount is always present. This is set according to the amounts of inorganic species in the aerosol.

In the extended AIM model described by Clegg (2004) the Gibbs energies of formation of the additional aqueous species $\mathrm{NH}_{3}$ and $\mathrm{OH}^{-}$are obtained, as a function of temperature, from the equilibrium constants for dissociation of water and of ammonium, and the Gibbs energies of formation of $\mathrm{H}_{2} \mathrm{O}, \mathrm{H}^{+}$, and $\mathrm{NH}_{4}^{+}$, using Eq. (11) of Wexler and Clegg (2002). The molality based dissociation constants of the surrogate organic species, their Henry's law constants or subcooled liquid vapour pressures $p_{i}^{o}$ and associated enthalpy changes are entered as input data to the program. Where $p_{i}^{o}$ is used, the logarithm of the infinite dilution activity coefficient in water $\left(f_{i}^{\infty}\right)$ and its slope with respect to temperature are also entered. These quantities are used internally within the program to calculate the Gibbs energies of formation used by the equilibrium solver. Activity coefficients determined using UNIFAC for the uncharged organic molecules in both liquid phases are converted to a reference state of infinite dilution with respect to water for use in Eq. (23) of Wexler and Clegg (2002). Values for the aqueous phase are adjusted, as are those of the ions and water, to take account of the alteration of the definition of the mole fractions in the solution to include all the species present, rather than just ions + water, or organics + water. The approach taken is described by Clegg et al. (2001). Primary surrogate compounds are constrained, in most calculations, to the hydrophobic phase. The dissociation of surrogates B1, B2, A1, A2 and A4 in the aqueous phase, to produce additional $\mathrm{H}^{+}$and organic anions, occurs only in the aqueous phase. The equilibrium state of each test system is determined by minimization of Eq. (23) of Wexler and Clegg (2002), with additional terms to account for the hydrophobic liquid phase.

\subsection{Solvent and solute activities}

In the UCD-CACM model the mean molal activity coefficients of the inorganic electrolytes present are calculated using the method of Kusik and Meissner (1978) as implemented by Wexler and Seinfeld (1991). The method is based upon the properties of the single electrolytes present, which are correlated with single parameter equations using data for $25^{\circ} \mathrm{C}$. The inorganic composition of the aerosol must be specified in terms of electrolyte molalities, rather than those of the aqueous ions, in order to calculate activity coefficients using the Kusik and Meissner method. These are obtained by assigning anions to cations in proportion to the cation charge $m_{i} z_{i}$ for cation $i$ divided by the total charge of all cations $\left(\Sigma_{i} m_{i} z_{i}\right)$, and the corresponding assignment of cations to anions. For the group of ions $\mathrm{Na}^{+}, \mathrm{NH}_{4}^{+}, \mathrm{H}^{+}, \mathrm{Cl}^{-}, \mathrm{NO}_{3}^{-}$, and $\mathrm{SO}_{4}^{2-}$ there are 9 possible electrolytes. This approach is the same as originally proposed by Reilly and Wood (1969), and also used by Clegg and Simonson (2001) in an activity coefficient model in which electrolytes rather than ions are treated as the basic components. The use of a very simple correlating equation for the thermodynamic properties of single solute solutions in the Kusik and Meissner method, the lack of treatment of mixture or temperature effects, and the lack of explicit recognition of the $\mathrm{HSO}_{4(\mathrm{aq})}^{-} \leftrightarrow \mathrm{H}_{(\mathrm{aq})}^{+}+\mathrm{SO}_{4(\mathrm{aq})}^{2-}$ equilibrium, make the method less accurate than the more complex, but computationally intensive, approaches used in AIM and in other atmospheric codes (e.g., Zhang et al., 2000; Nenes et al., 1998; Jacobson, 1997).

In the UCD-CACM model, osmotic coefficients of aqueous electrolytes from Tang et al. (1997) are used to calculate the equilibrium water activities and vapour pressures of each aerosol size bin using the Zdanovskii-Stokes-Robinson (ZSR) relationship (Stokes and Robinson, 1966; Seinfeld and Pandis, 2006). The water associated with the organic compounds in the aqueous phase is calculated using UNIFAC (Fredenslund, 1975). As noted above, water exchange between the aerosol and the gas phase is controlled dynamically, as it is for all volatile species, and is also subject to two limits: the aerosol water content of each size bin is not allowed to fall below a minimum value which is related to the amounts of inorganic solutes present, nor is the ionic strength permitted to rise above $100 \mathrm{~mol} \mathrm{~kg}^{-1}$.

In the extended AIM model both solute and solvent activity coefficients are estimated for mixed inorganic/organic aqueous solutions by the method described by Clegg et al. (2001). The Pitzer-Simonson-Clegg (PSC) equations (Clegg et al., 1992) are used for the inorganic component of the solution and UNIFAC for the uncharged organic species in the aqueous phase of the aerosol, and for all components in the hydrophobic phase. Both mixture effects (between inorganic ions) and the variation of activity coefficients with temperature are taken into account in the PSC model, which yields values of single ion activity coefficients. The sulphate/bisulphate equilibrium is also treated explicitly, with 


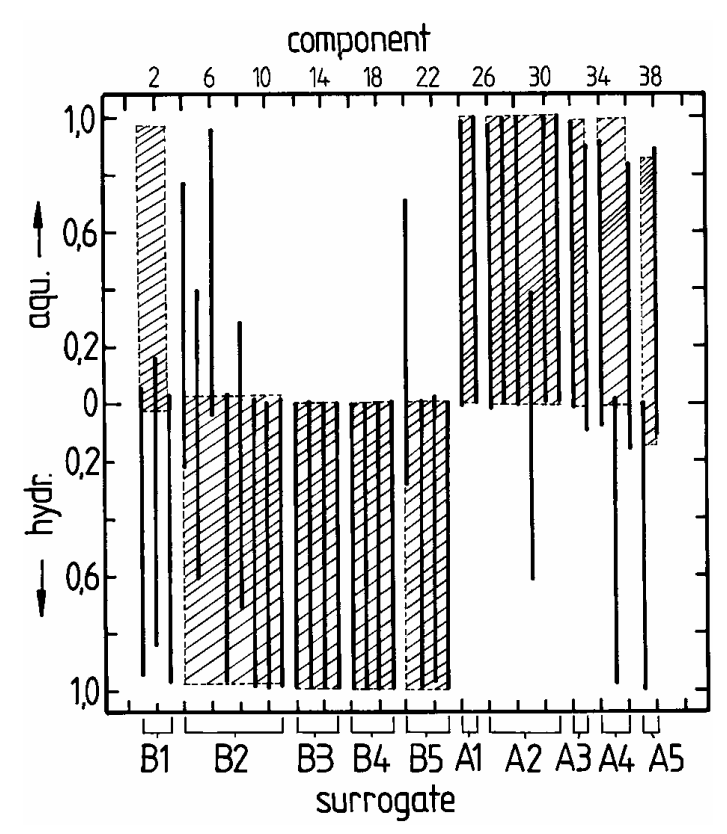

Fig. 2. Calculated fractional partitioning of 0.01 moles of surrogates B1-5, A1-5, and the 38 compounds assigned to them, in a system containing 1 mole of water and 1 mole of P8. Solid vertical lines show partitioning of the individual components. For example, about $0.95(95 \%)$ of component 1 (upper $\mathrm{x}$-axis) is present in the hydrophobic P8 phase at equilibrium, and a fraction of $0.05(5 \%)$ in the aqueous phase. The hatched boxes indicate the calculated partitioning of the surrogates (lower $\mathrm{x}$-axis) to which the individual compounds are assigned. For example, over $95 \%$ of $\mathrm{B} 1$ is calculated to occur in the aqueous phase, whereas the three components assigned to it are present mainly in the hydrophobic phase. The component assignments are given in the notes to Table 8 of Paper 2 .

$\mathrm{HSO}_{4(\mathrm{aq})}^{-}$as a separate ionic species (Clegg and Brimblecombe, 1995). Aerosol water content is calculated as a part of the minimisation of the total Gibbs energy of the system that is used to calculate its equilibrium state at fixed $T$ and $\mathrm{RH}$, and can be zero (corresponding to an aerosol containing only inorganic solids).

The UCD-CACM inorganic aerosol model includes inorganic ions $\mathrm{Na}^{+}, \mathrm{NH}_{4}^{+}, \mathrm{H}^{+}, \mathrm{Cl}^{-}, \mathrm{NO}_{3}^{-}$, and $\mathrm{SO}_{4}^{2-}$, although the treatment of these species is somewhat approximate (see previous discussion). The inorganic model used in the $A I M$ calculations is that for $\mathrm{H}^{+}-\mathrm{NH}_{4}^{+}-\mathrm{SO}_{4}^{2-}-\mathrm{NO}_{3}-\mathrm{H}_{2} \mathrm{O}$ (AIM Model II on the web site http://www.uea.ac.uk/ e770/ aim.html). This has been modified for use in this study in two ways. First, the equilibria $\mathrm{H}_{2} \mathrm{O}_{(1)} \leftrightarrow \mathrm{H}_{(\mathrm{aq})}^{+}+\mathrm{OH}_{(\mathrm{aq})}^{-}$, and $\mathrm{NH}_{4(\mathrm{aq})}^{+} \leftrightarrow \mathrm{NH}_{3(\mathrm{aq})}+\mathrm{H}_{(\mathrm{aq})}^{+}$, have been added so that $\mathrm{OH}^{-}$and $\mathrm{NH}_{3}$ are additional aqueous phase species. No interaction parameters for these species in the PSC model have yet been determined. The activity coefficients are calculated using Eqs. (17), (26) and (31) for $\mathrm{OH}^{-}$(which includes the DebyeHückel limiting law), and Eq. (15) for $\mathrm{NH}_{3}$, from Clegg et al. (1992). The aerosols simulated in this study also contain
$\mathrm{Na}^{+}$and $\mathrm{Cl}^{-}$. We have therefore included parameters for $\mathrm{Na}^{+}$interactions with $\mathrm{SO}_{4}^{2-}, \mathrm{HSO}_{4}^{-}, \mathrm{NO}_{3}^{-}$and $\mathrm{Cl}^{-}$at $25^{\circ} \mathrm{C}$ from AIM Model III (Clegg et al., 1998b), for $\mathrm{Cl}^{-}$with $\mathrm{H}^{+}$ as a function of temperature from Model I (Carslaw et al., 1995), and for interactions of $\mathrm{Cl}^{-}$with $\mathrm{Na}^{+}$and $\mathrm{NH}_{4}^{+}$from Model III. Ternary (mixture) interaction parameters were also taken from Model III, where available. The variation of the Henry's law constant of $\mathrm{HCl}$ with temperature is taken from Model I. Organic acid anions from the dissociation of surrogates were incorporated into the model by assuming that the parameters for their interactions with cations are the same as those for $\mathrm{SO}_{4}^{2-}$ (doubly charged anions) or $\mathrm{HSO}_{4}^{-}$(singly charged anions).

The UNIFAC group interaction parameters used by both models in this study, for the organic aerosol components, are those listed in the Supplementary Material to Hansen et al. (1991), and do not include later additions. UNIFAC group definitions for each organic surrogate molecule in the UCD-CACM model are listed in Appendix A. We note that the structure $-\mathrm{O}-\mathrm{NO}_{2}$ cannot be defined in terms of the currently available groups, and substitutions have been made for this study. Also, parameters for some interactions are unknown (see Appendix A). The effects of these uncertainties have not been quantified. The partitioning of SOA surrogate compounds A1-5 and B1-5 between the aqueous and hydrophobic phases in the aerosol is driven by the activity coefficients, estimated using UNIFAC, for the two systems A1-5 and B1-5 plus water (aqueous phase) and A1-5 and B1-5 plus P1-8 (hydrophobic organic phase). The governing equation is simply Eq. (1) for the mole fraction and activity coefficient of each component $i$ in the two phases.

The UNIFAC equations are based upon functional groups, and smaller structural units, as the fundamental entities in solution from which all molecules present are made up. Consequently, the assignment of individual semi-volatile compounds to the surrogates used in the UCD-CACM or other models - where these surrogates are based upon structural similarities - is likely to produce results that are consistent with those that would be obtained for the individual compounds. We have tested this by calculating liquid/liquid partitioning for a system containing 1 mole of water, 1 mole of P8 (the dominant hydrophobic compound in the trajectory calculations discussed further below), and 0.01 moles of each of the thirty eight compounds making up the ten surrogates A1-5 and B1-5. The results, see Fig. 2, show broad agreement: the components of A1-5 occur mainly in the aqueous phase, and most of the components of B3 to B5 occur in the hydrophobic phase, which is consistent with the calculated partitioning of the surrogates. Agreement is poorer for B2, and the components of B1 appear to have a mainly hydrophobic nature whereas B1 itself is predicted to be water soluble. This is likely to be due to the chosen locations of the functional groups on the surrogate molecules, which contain similar groups and have similar molecular formulae to the molecules they represent. We note that in 


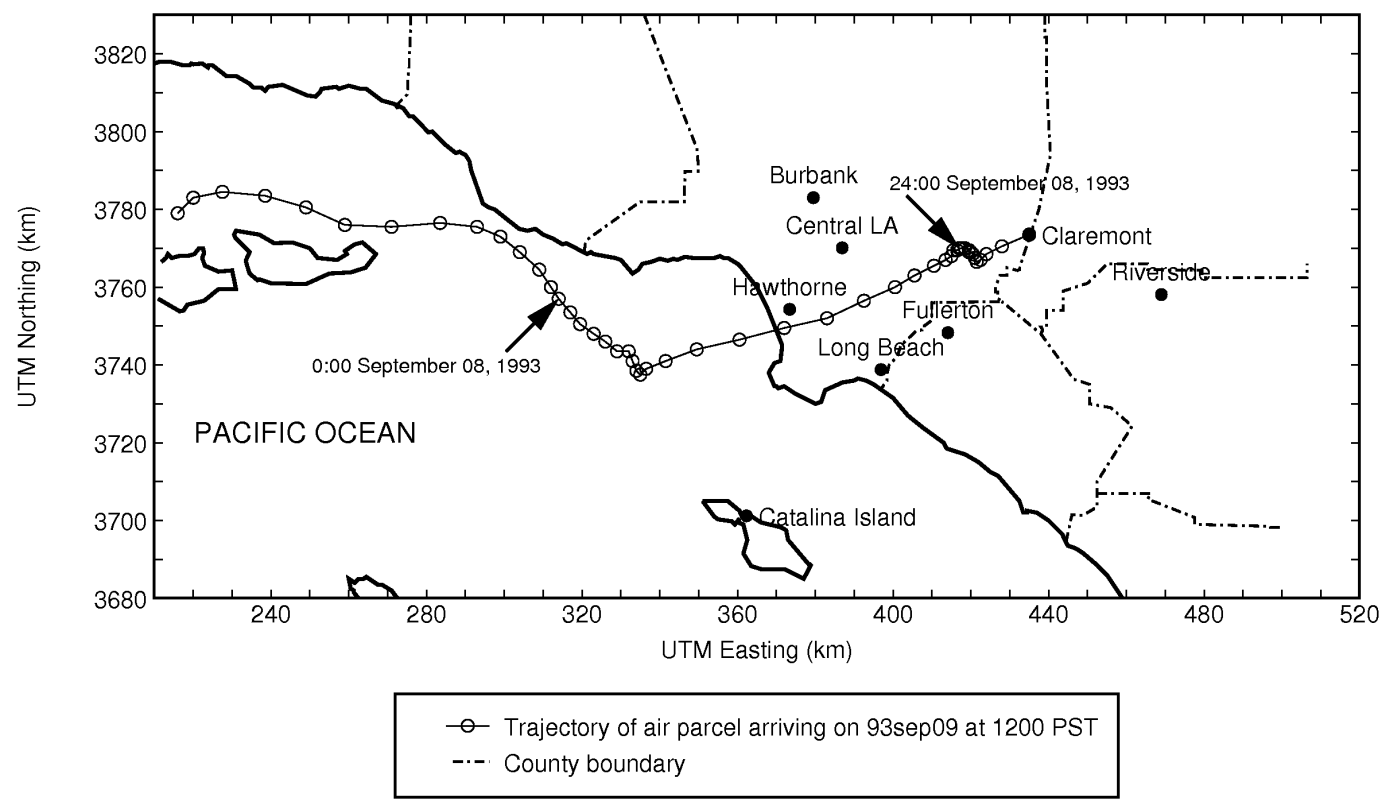

Fig. 3. Calculated trajectory path for the air parcel arriving at Claremont CA at 12:00 PST on 9 September 1993.

aerosols at moderate to high RH the amount of liquid water is likely to greatly exceed the amount of hydrophobic material present; consequently in the trajectory calculations discussed further below a significant fraction of total aerosol B2 can be found in the aqueous phase despite the small aqueous fraction shown in Fig. 2.

Our original intent when planning this study was to focus on salt/organic interactions in the aqueous phase, usually referred to as "salting in" or "salting out", which is an element of the activity coefficient modelling of the aqueous phase that affects steps (b) (c) and (d) in Fig. 1. This behaviour has been studied in measurements of deliquescence relative humidity (DRH) and solubility in mixtures of dicarboxylic acids and salts (e.g., Marcolli et al., 2004; Salcedo, 2006; Clegg and Seinfeld, 2006a, b and references therein). The effect on DRH is already predicted, at least approximately, by current methods of estimating aerosol water content (Clegg and Seinfeld, 2006a), and the salt effect on the activity coefficients of organic solutes is probably smaller in magnitude than uncertainties related to vapour pressures, the choice of surrogate species and the choice of activity coefficient model. Furthermore, it is difficult to include such interactions in models in a reliable and robust way to very high (supersaturated) concentrations. Salt/organic interactions have therefore been omitted here.

In the absence of activity coefficient model parameters for interactions between ions and undissociated organic molecules, noted above, the extended AIM model yields molality based activity coefficients for both types of species that are unaffected by the presence of the other (see Eqs. 1a and b of Clegg et al., 2001). The approach in the UCD-CACM model, described by Pun et al. (2002), is found to be equivalent when the definitions of mole fractions and mole fraction activity coefficients used in the computer code are taken into account. However, there are some differences between the two models. First, organic and inorganic activity coefficient calculations in the UCD-CACM model are not fully coupled with respect to $\mathrm{pH}$. Inorganic liquid/solid equilibria are solved first, followed by those involving the organic compounds: uptake of water, the dissociation of the acid surrogate species and partitioning between the two aerosol phases. The $\mathrm{H}^{+}$ion concentration in the aqueous phase is modified (increased) by the dissociation of the organic acids, but this change is not fed back into the inorganic calculation. In most situations the amounts of water-soluble dissociating organic compounds in the aerosol are small relative to the inorganic content, so the effect of this simplification is likely to be negligible. (A possible exception is where the aerosol is close to neutral $\mathrm{pH}$, in which case the organic compounds could be a significant source of $\mathrm{H}^{+}$and so influence equilibria with gas phase $\mathrm{NH}_{3}, \mathrm{HNO}_{3}$ and $\mathrm{HCl}$.)

Second, in the UCD-CACM model the values of the activity coefficients of the organic acid molecules and anions in Eq. (3), required to calculate dissociation, are both assumed to be equal to the value obtained using UNIFAC for the undissociated molecule. This is equivalent to assuming values of unity, since the activity coefficients in the equations cancel. The value of $\gamma \mathrm{H}^{+}$is also assumed to be unity. We note that Pun et al. (2002) assumed unit values for only the activity coefficients of $\mathrm{H}^{+}$and the organic anions in Eq. (3). The effect of the treatment of activity coefficients in the UCD-CACM model is to lower the dissociation of organic 

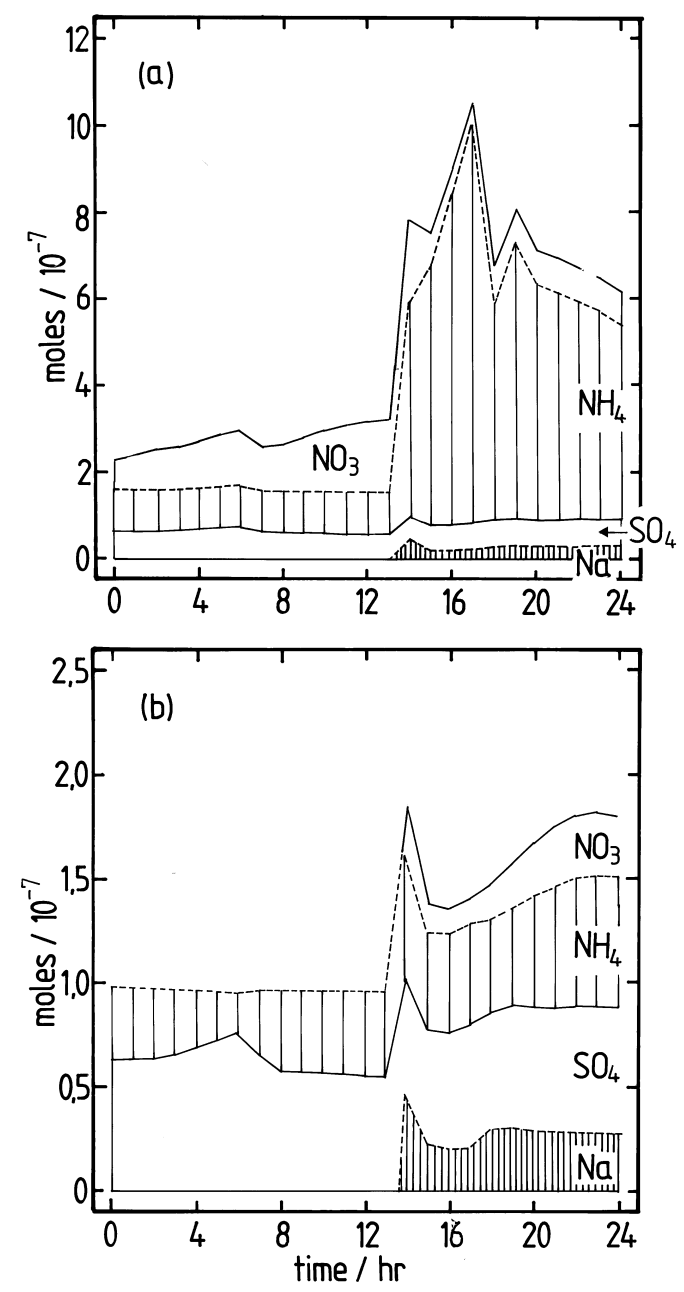

Fig. 4. Inorganic composition of the air parcel in $\mathrm{mol} \mathrm{m}^{-3}$, over the diurnal cycle on 8 September 1993 shown in Fig. 3. Amounts are plotted above each other so that the vertical extent of each of the four areas corresponds to the amount of that species present, e.g., the amount of $\mathrm{SO}_{4}^{2-}$ at time zero in both plots is about $0.6 \times 10^{-7} \mathrm{~mol} \mathrm{~m}^{-3}$. The amount of chloride present in the system on these scales is negligible and not shown, and the areas marked $\mathrm{NH}_{4}$ are total ammonia $\left(\mathrm{NH}_{4}^{+}\right.$and $\left.\mathrm{NH}_{3}\right)$. (a) Total amounts in the aerosol and gas phases; (b) amounts present in the aerosol (UCDCACM model results for level 1 , which is closest to ground).

acids, and this is discussed further below. The effect will vary with both aerosol composition and concentration.

\subsection{Vapour pressures}

In the UCD-CACM model, subcooled vapour pressures of secondary organic surrogates A1-5 and B1-5 are estimated by the method of Myrdal and Yalkowsky (1997). This uses the boiling temperature at atmospheric pressure $\left(T_{b}\right)$, the entropy of boiling $\left(\Delta S_{b}\right)$, and the heat capacity change upon boiling $\left(\Delta C_{p}^{(g l)}\right)$. The normal boiling points used in previous applications of the UCD-CACM model were obtained either from measurements or using the estimation software of Advanced Chemistry Developments (ACD) which is described in a manuscript by Kolovanov and Petrauskas (undated) ${ }^{1}$, (B. L. Hemming, personal communication). Full details, and a comparison with other boiling point and vapour pressure prediction methods, are given in Paper 2 (Clegg et al., 2008).

\subsection{Key uncertainties}

Within the scheme shown in Fig. 1 - omitting both gas phase reaction mechanisms and step (e) from consideration - the main uncertainties affecting gas/aerosol partitioning are associated with the vapour pressures of the semi-volatile compounds, the approximations inherent in the use of surrogate compounds, and calculations of aerosol water content and activities in the liquid aerosol. First, realistic predictions of gas/aerosol partitioning of the semi-volatile organic compounds require accurate estimates of $p^{o}$, and the associated enthalpy of vaporisation $\Delta H_{\text {vap }}^{o}$ of the compounds or their surrogates. The available methods for vapour pressure prediction, which are based upon the structure and functional group composition, are least accurate for compounds containing polar groups, and yield widely varying results (see Paper 2, Clegg et al., 2008).

Second, the choice of surrogate species, and their structures and functional group compositions, are also important. Table 1 of Paper 2 lists vapour pressures for butane and related $\mathrm{C}_{4}$ alcohols and carboxylic acids. The addition of first one, and then two polar functional groups to the butane molecule results in a lowering of $p^{o}$ by orders of magnitude. The positions of the groups on the molecule also make a large difference to the vapour pressure, by more than an order of magnitude in some of the examples shown in the table. Consequently, if the properties of the surrogate species are averages of the estimated values of the compounds they represent, then the range is likely to be large.

Third, it is known that UNIFAC, which is used in both models in this study to calculate liquid phase activities of the organic compounds in the aerosol, is least accurate for molecules containing polar functional groups. In addition, assumptions about the activity coefficients of organic anions in Eq. (3a, b) need to be made in order to calculate dissociation. It is also worth noting that both models used here to calculate activity coefficients ignore interactions that may occur between the two inorganic and organic (uncharged) species, partly due to a lack of data and partly because of the lack of a satisfactory way of representing them over very wide ranges of concentration. We examine the effects of these uncertainties below.

\footnotetext{
${ }^{1}$ Kolovanov, E. and Petrauskas, A.: Towards the maximum accuracy for boiling point prediction, undated manuscript.
} 

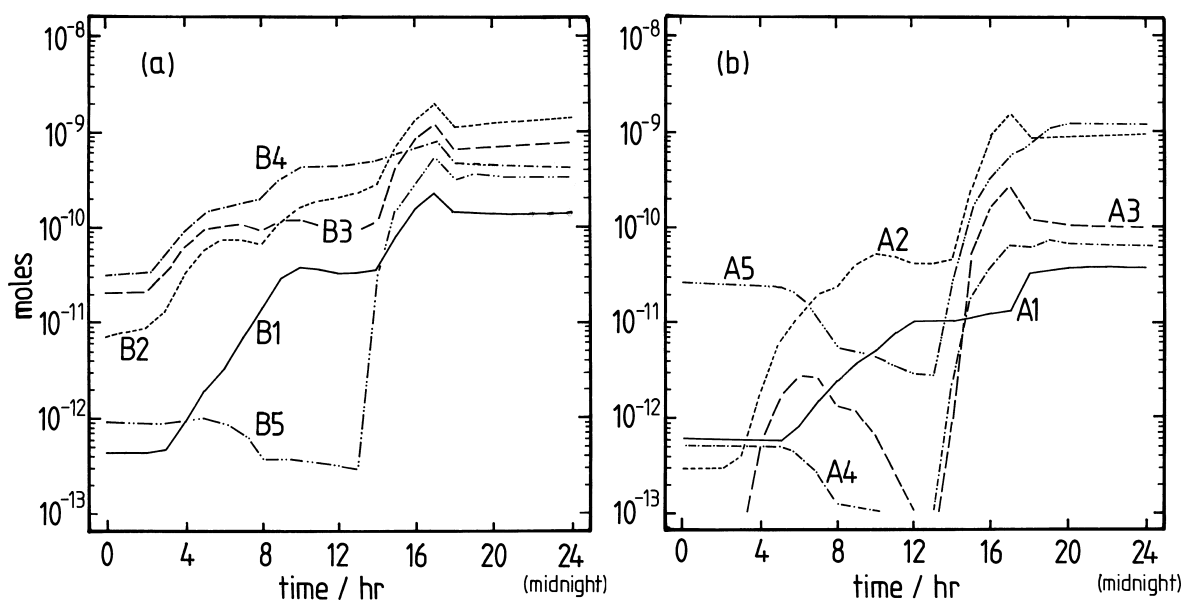

Fig. 5. Total amounts $\left(\mathrm{mol} \mathrm{m}^{-3}\right)$ in the gas and aerosol phases of each of the semi-volatile surrogate species during the simulated diurnal cycle, UCD-CACM level 1 results. (a) B1-5; (b) A1-5.

\section{Comparisons}

\subsection{Atmospheric simulations (base case)}

Here we focus mainly on a single diurnal cycle from time 00:00 to 24:00 PST on 8 September 1993, for the trajectory shown in Fig. 3. Over this period the air parcel travels from over the Pacific Ocean to central Los Angeles and then to Claremont. Both total (gas + aerosol) and aerosol amounts of $\mathrm{SO}_{4}^{2-}, \mathrm{NH}_{4}^{+}, \mathrm{NO}_{3}^{-}$and $\mathrm{Na}^{+}$, from level 1 of the UCD-CACM model simulation (from zero to $38 \mathrm{~m}$ above ground), are shown in Fig. 4. The amounts of $\mathrm{SO}_{4}^{2-}, \mathrm{Na}^{+}$, and also $\mathrm{NH}_{4}^{+}$in the aerosol (because $\mathrm{H}^{+}$is only present in a small amount, and because of the overall requirement of electroneutrality) are essentially fixed. There is a small addition of sea salt to the aerosol as the parcel reaches the coast at 13:00 PST, and large addition of ammonia which peaks as the parcel passes over the Chino dairy region at 18:00 PST and reaches Claremont the next day. Figure 5 shows the total concentrations of the 10 semi-volatile surrogate species over the diurnal cycle. Of the surrogates A1-5, A5 dominates in the early morning, $\mathrm{A} 2$ during the middle of the day, and both A2 and A5 in the evening. The B surrogate species present in the highest total concentrations are B2-4, and the amounts increase over the course of the diurnal cycle as the air parcel encounters anthropogenic emissions. Surrogate P8 constitutes well over $90 \mathrm{~mol} \%$ of the involatile primary organic compounds present in the system and occurs at highest concentration late in the day.

Values of $T$ and RH are shown in Fig. 6 for the diurnal cycle. Relative humidity ranges from about $40 \%$, for which the acid sulphate aerosols would be expected to contain very little water or exist as dry crystals, to $80 \%$ which is the deliquescence $\mathrm{RH}$ of ammonium sulphate over the relatively narrow range of temperature ( 289 to $301 \mathrm{~K}$ ) experienced in this

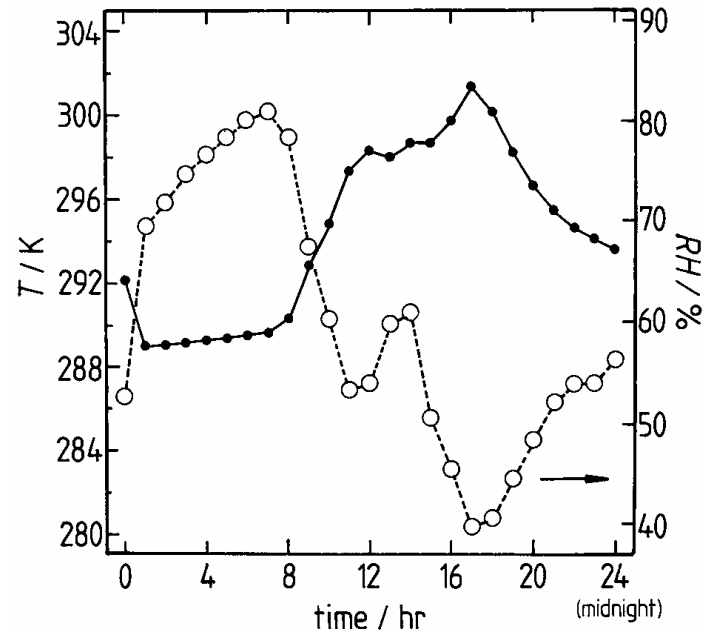

Fig. 6. Atmospheric temperature (solid line, left axis) and relative humidity (dashed line, right axis) from ground level to $38 \mathrm{~m}$, for the trajectory shown in Fig. 3.

cycle. At this higher RH the acid sulphate aerosol particles are fully liquid.

In the next section, the aggregate aerosol composition (the sum of the contents of bins 6 to 15) and the range of composition across the particle size spectrum are examined and model results compared. The effects of differences in the inorganic elements of the thermodynamic models on aerosol composition and partitioning of $\mathrm{NH}_{3}, \mathrm{HNO}_{3}$ and the semivolatile organic compounds are also discussed.

\subsubsection{Inorganic component behaviour}

In the first set of model comparisons, the total amounts of all species in each of the 10 aerosol size bins were fixed to the values calculated by the UCD-CACM model. The 


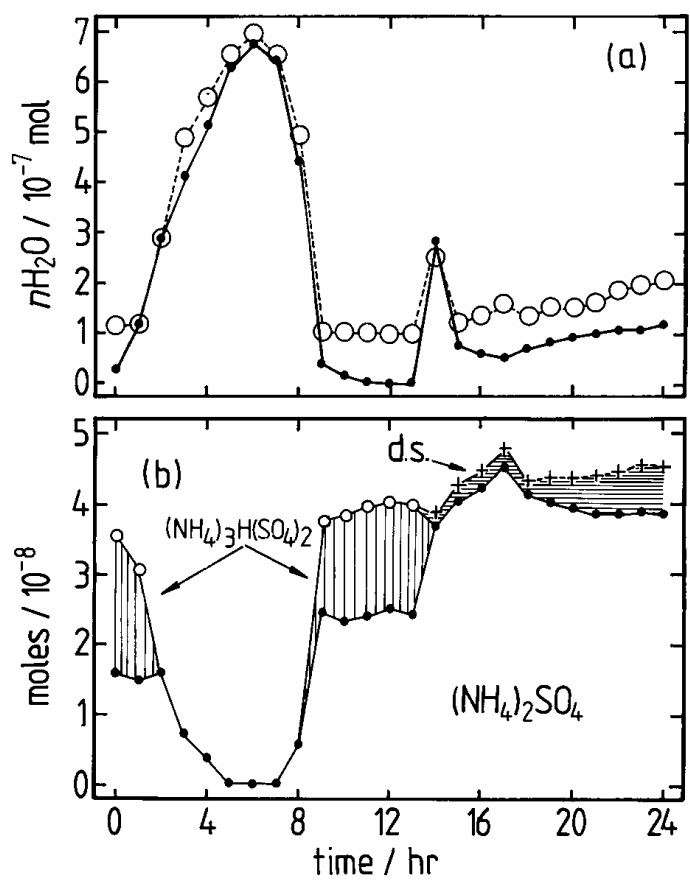

Fig. 7. (a) Total moles of water $\left(n \mathrm{H}_{2} \mathrm{O}\right)$ in the aerosol phase, per $\mathrm{m}^{3}$ of atmosphere, for size bins 6 to 15 . Solid line - AIM model; dashed line and open circle - UCD-CACM model, based upon the total moles of solutes in each bin predicted by the UCD-CACM model. (b) Moles of inorganic solids calculated by AIM for each aerosol size bin, summed. Dots $-\left(\mathrm{NH}_{4}\right)_{2} \mathrm{SO}_{4(\mathrm{~s})}$; open circles $\left(\mathrm{NH}_{4}\right)_{2} \mathrm{SO}_{4}$ (s) plus letovicite; plus - $\left(\mathrm{NH}_{4}\right)_{2} \mathrm{SO}_{4}$ (s) and the double salt (d.s.) $2 \mathrm{NH}_{4} \mathrm{NO}_{3}$. $\left(\mathrm{NH}_{4}\right)_{2} \mathrm{SO}_{4}$ (s). At time 0:00 there are about $1.7 \times 10^{-8}$ moles of $\left(\mathrm{NH}_{4}\right)_{2} \mathrm{SO}_{4}(\mathrm{~s})$ and $1.9 \times 10^{-8}$ moles of letovicite.

equilibrium properties of the aerosol in each size bin, including partitioning between the aqueous and hydrophobic phases and the formation of solids, were then recalculated using AIM.

The total amounts of aerosol water, the sum of the values in bins 6 to 15 ( 0.1 to $10 \mu \mathrm{m}$ size range), calculated by both models over the diurnal cycle are shown in Fig. 7a. For RH above about $60 \%$ (from midnight to 8 or 9 a.m.) the totals agree closely. For the whole of the cycle the amounts of organic surrogate compounds in the aerosol are small, as is nitrate, and the small differences in total water for high RH reflect differences in the representation of the thermodynamic properties of acid ammonium sulphate by the two models and the fact that partitioning of water is calculated dynamically in the UCD-CACM model and equilibrium is not assumed. After 09:00 a.m., as RH falls, the AIM reference model predicts consistently less water in the aerosol which dries out (all size bins) between about 09:00 a.m. and 01:00 p.m. During this period the water contents of all the aerosol bins in the UCDCACM model reach their lower permitted limits. The solids predicted by the AIM model are shown in Fig. 7b. From

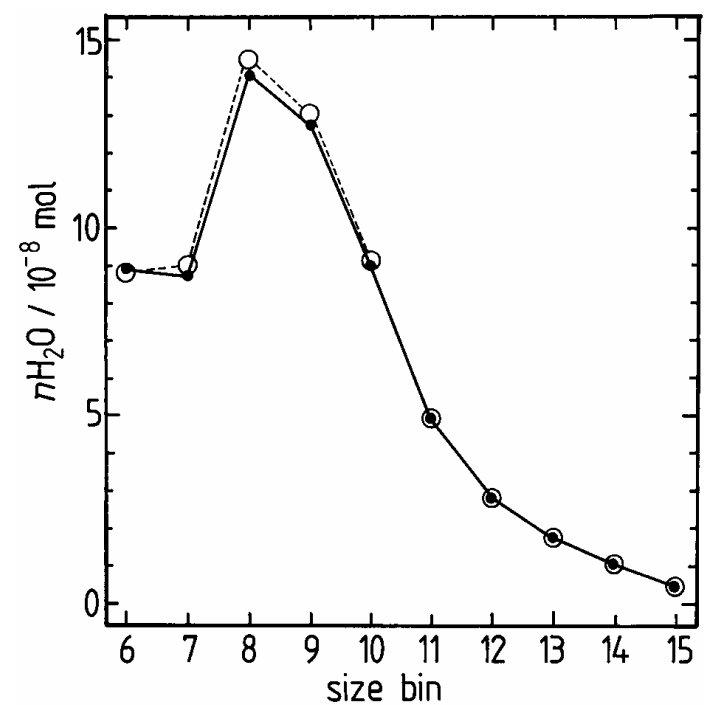

Fig. 8. Total moles of water $\left(n \mathrm{H}_{2} \mathrm{O}\right)$ in the aerosol phase, per $\mathrm{m}^{3}$ of atmosphere, for each of size bins 6 to 15, at 08:00 a.m. Solid line UCD-CACM model; dashed line and open circle - AIM model for the total moles of solutes in each bin predicted by the UCD-CACM model.

01:00 a.m. to 08:00 a.m., for which the predicted total water amounts of the two models agree closely, the only solid that occurs is $\left(\mathrm{NH}_{4}\right)_{2} \mathrm{SO}_{4(\mathrm{~s})}$. The smaller amounts of water predicted by AIM at midnight, and the drying out of the aerosol between 09:00 a.m. and 01:00 p.m., are associated with the formation of letovicite. After 02:00 p.m. AIM again predicts less aerosol water than does the UCD-CACM model. This difference is associated both with the lower limit of aerosol water being reached in the UCD-CACM model, and with the formation of double salt $2 \mathrm{NH}_{4} \mathrm{NO}_{3}$. $\left(\mathrm{NH}_{4}\right)_{2} \mathrm{SO}_{4}$ (s) in addition to $\left(\mathrm{NH}_{4}\right)_{2} \mathrm{SO}_{4(\mathrm{~s})}$ being predicted by AIM. The double salt is not included in the UCD-CACM model.

We further compared the inorganic thermodynamic elements of the two models by examining the calculated equilibrium properties of the aerosol across all the size bins at 08:00 a.m. ( $T=289.6 \mathrm{~K}, \mathrm{RH}=0.8098$ ), for which both models predict all particle size bins to be fully liquid. The aerosol water contents predicted by both models are shown in Fig. 8 for all size bins and agree well. Over $80 \%$ of the total water mass resides in bins 6 to 10. The inorganic composition of the aerosol, Fig. 9, varies from approximately $\mathrm{NH}_{4} \mathrm{HSO}_{4}$ (i.e., $\left.1: 1\left(\mathrm{NH}_{4}\right)_{2} \mathrm{SO}_{4}: \mathrm{H}_{2} \mathrm{SO}_{4}\right)$ for bins 6 and 7 to slightly acidified ammonium sulphate at the largest sizes. The small amount of $\mathrm{NO}_{3}^{-}$present peaks in bins 8 to 12 , but is present in greatest proportion in the higher numbered bins. We note that $3.3 \times 10^{-9} \mathrm{~mol} \mathrm{~m}^{-3}$ of the non-volatile primary organics, mainly $\mathrm{P} 8$, are present in the hydrophobic phase, and a total of $2.0 \times 10^{-11}$ moles of SOA surrogates A1-5 and B1-5 are distributed between the two liquid phases. These amounts are very small compared to the inorganic content of the aerosol. 

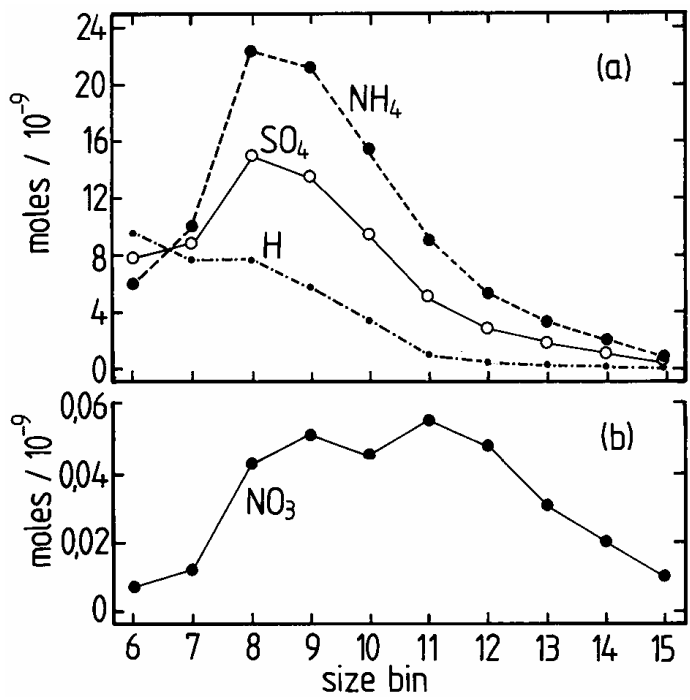

Fig. 9. The inorganic composition of each aerosol size bin at time 08:00 a.m. predicted by the UCD-CACM model. (a) Amounts of $\mathrm{NH}_{4}^{+}, \mathrm{SO}_{4}^{2-}$ and $\mathrm{H}^{+}$; (b) amount of $\mathrm{NO}_{3}^{-}$(reduced scale).

How do the models vary in their prediction of equilibrium partial pressures of $\mathrm{HNO}_{3}$ and $\mathrm{NH}_{3}$ across the size bins, and how do these compare with the actual amounts of $\mathrm{NH}_{3}$ and $\mathrm{HNO}_{3}$ in the gas phase (which will be different if the two phases are not at thermodynamic equilibrium)? Figure 10 shows the relative compositions of the size bins, at 08:00 a.m., and the ratios of the equilibrium partial pressures of $\mathrm{HNO}_{3}$ and $\mathrm{NH}_{3}$ calculated by AIM to both the UCDCACM model results and the calculated equilibrium partial pressures of $\mathrm{HNO}_{3}$ and $\mathrm{NH}_{3}$ used by the UCD-CACM model to drive inter-phase transport. In the UCD-CACM simulation all size bins are at equilibrium with $\mathrm{HNO}_{3(\mathrm{~g})}$ $\left(2.33 \times 10^{-9} \mathrm{~atm}\right)$ as indicated by the overlap of the $\mathrm{HNO}_{3}$ curves in Fig. 10. However, none of the aerosol bins, except 10 , are at equilibrium with $\mathrm{NH}_{3(\mathrm{~g})}$, which is present at a pressure of only $5.51 \times 10^{-12}$ atm.

The partial pressures calculated using the two models agree most closely for bin 6 which has a composition $\left(\mathrm{NH}_{4}\right)_{0.76} \mathrm{H}_{1.24} \mathrm{SO}_{4}$ plus trace $\mathrm{HNO}_{3}$. Here $\mathrm{pHNO}_{3}(A I M)$ is about $1 / 2$ of the value predicted by the UCD-CACM thermodynamic code, and $\mathrm{pNH}_{3}(A I M)$ is about $1.5 \times$ the UCD$\mathrm{CACM}$ value. In the larger size bins, as composition tends more towards $\left(\mathrm{NH}_{4}\right)_{2} \mathrm{SO}_{4}$, the differences between the equilibrium partial pressures predicted by the two models increase: $\mathrm{pHNO}_{3}(A I M)$ is lower by almost a factor of 10 and $\mathrm{pNH}_{3}($ AIM) greater by a factor of 20 . The reasons for this are investigated in Appendix B, by comparing predictions of both models to data yielding the reciprocal $\left(\gamma \mathrm{NH}_{4}^{+} / \gamma \mathrm{H}^{+}\right)$in aqueous ammonium sulphate solutions. Results suggest that $\gamma \mathrm{H}^{+}$, and the activity $m \mathrm{H}^{+} \times \gamma \mathrm{H}^{+}$, are not predicted well by the Kusik and Meissner (1978) method used for inorganic thermodynamic properties in the UCD-CACM model. The
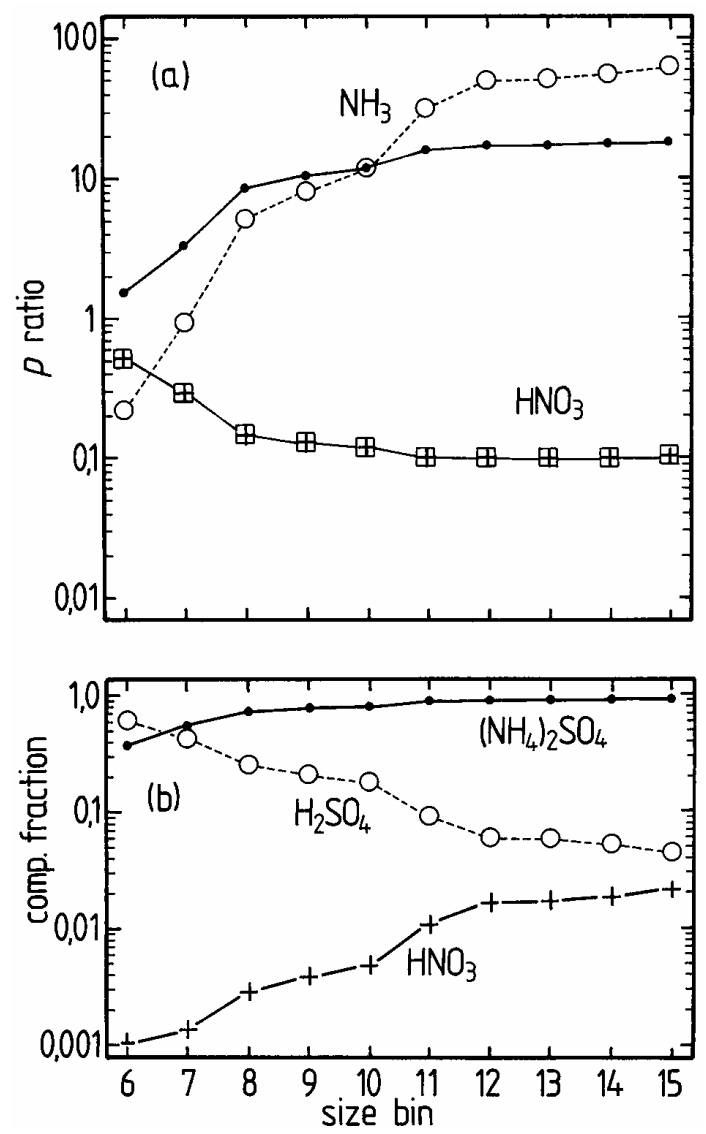

Fig. 10. (a) The equilibrium partial pressures of $\mathrm{NH}_{3}$ and $\mathrm{HNO}_{3}$ over each aerosol size bin calculated by AIM, divided by the actual partial pressures in the gas phase from the UCD-CACM model and the equilibrium values calculated by the UCD-CACM model for the same aerosol compositions (08:00 a.m.). A value of unity for the ratio indicates agreement between the two models. Dot and solid line $-\mathrm{NH}_{3}$, for the UCD-CACM calculated equilibrium partial pressure; open circle and dotted line $-\mathrm{NH}_{3}$, for the actual gas phase amount in the UCD-CACM model result; plus and solid line - $\mathrm{HNO}_{3}$, for the UCD-CACM calculated equilibrium partial pressure; open square and solid line $-\mathrm{HNO}_{3}$, for the actual gas phase amount in the UCD-CACM model result. (b) Aerosol composition, expressed as the fractional contributions (on a molar basis) of $\left(\mathrm{NH}_{4}\right)_{2} \mathrm{SO}_{4}, \mathrm{H}_{2} \mathrm{SO}_{4}$ and $\mathrm{HNO}_{3}$.

limitations of the approach - notably the use of single parameter equations to correlate the activity coefficients of aqueous electrolytes (Wexler and Seinfeld, 1991) and especially the inability to treat inorganic acid-base equilibria - suggest that these inaccuracies persist over a wide range of aerosol composition.

Having identified these differences between the thermodynamic models, it is also important to understand their practical impact, if any, in atmospheric simulations. In general, the effect of the inaccuracies on calculated $\mathrm{NH}_{3}$ and $\mathrm{HNO}_{3}$ partitioning will be greatest in situations where their distribution 


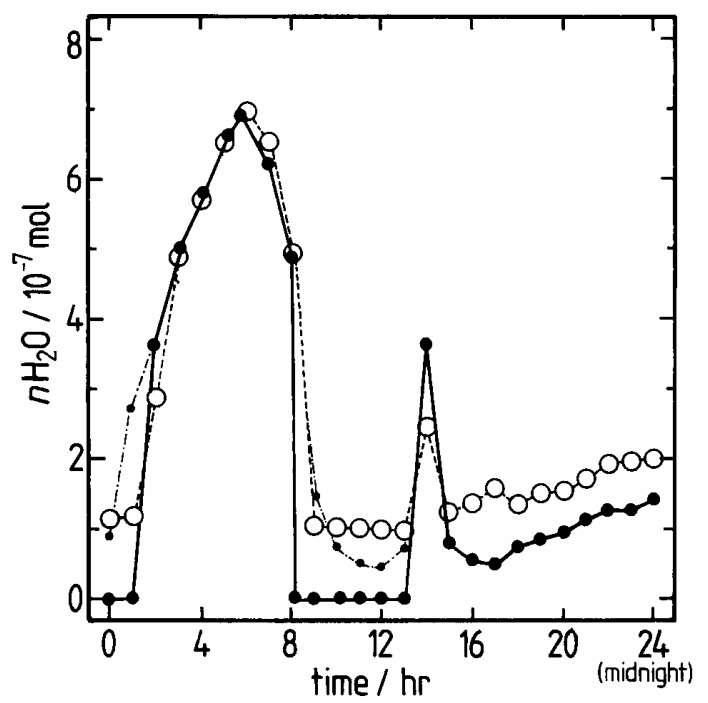

Fig. 11. Calculated aerosol water content, per $\mathrm{m}^{3}$ of atmosphere, over the diurnal cycle. Open circle and dashed lines - results from the UCD-CACM model, as shown in Fig. 7; dot and solid line the result from AIM for a gas/aerosol equilibrium partitioning calculation including all species and an aggregate composition equal to the total amounts of each species in the gas phase and in size bins 6-15; small dot and dash-dot line - result from AIM but where $\left(\mathrm{NH}_{4}\right)_{2} \mathrm{SO}_{4(\mathrm{~s})}$ is the only solid allowed to form.

between the aerosol and gas phases is relatively evenly balanced. For example, consider a case in which $99 \%$ of $\mathrm{HNO}_{3}$ in an air parcel is present in the gas phase, and the aerosol and gas phases are approximately at equilibrium. Even order of magnitude changes in the calculated equilibrium $\mathrm{pHNO}_{3}$ above the aerosol would only result in either a reduction of gas phase $\mathrm{HNO}_{3}$ by a few percent of the total, or an increase to a value greater than $99 \%$. The effects of the thermodynamic differences in the atmospheric simulation carried out here are small, as will be shown in comparisons of calculated $\mathrm{HNO}_{3}$ and $\mathrm{NH}_{3}$ partitioning further below.

Next we compare the results of full gas/aerosol partitioning calculations using AIM with the output of the UCDCACM model for the complete diurnal cycle. Note that the AIM model was only used to recalculate the equilibrium state of the system predicted by the UCD-CACM model (i.e., the total gas plus aerosol phase inorganic and organic species amounts per $\mathrm{m}^{3}$ of atmosphere). The purpose of this, for the inorganic components, is to examine both the effects of differences between the models on solids formation and, in particular, on gas/aerosol partitioning of $\mathrm{HNO}_{3}$ and $\mathrm{NH}_{3}$.

In the AIM calculations the system is assumed to consist of a gas phase and a single bulk aerosol with the aqueous and hydrophobic portions in equilibrium with each other, with any solids formed, and with the gas phase. The system contains the same total amounts of each species per $\mathrm{m}^{3}$ at each time point as in the UCD-CACM model, i.e. the amounts of

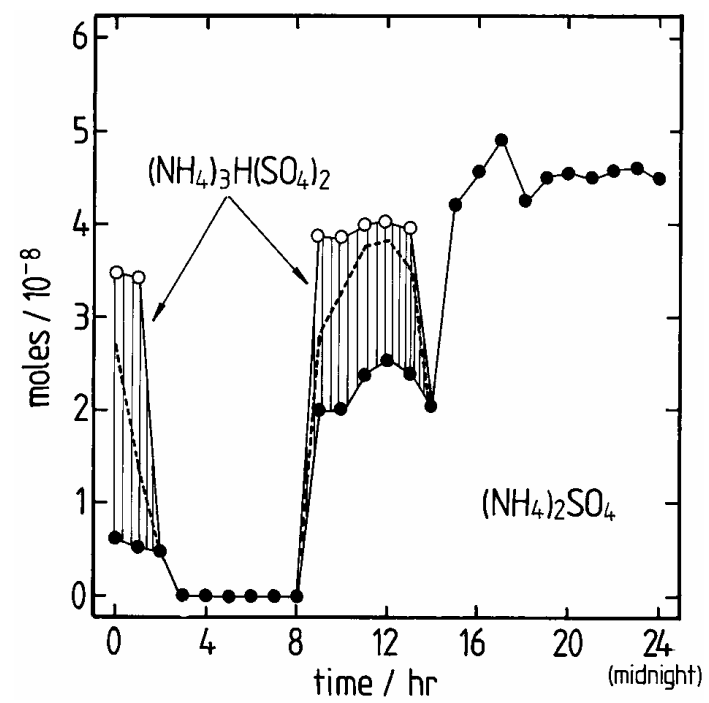

Fig. 12. Moles of inorganic solids calculated by AIM over the diurnal cycle. Note that, for the aggregated aerosol composition modelled for this case, the double salt seen in Fig. 7 does not occur. Dots - $\left(\mathrm{NH}_{4}\right)_{2} \mathrm{SO}_{4(\mathrm{~s})}$; open circles - $\left(\mathrm{NH}_{4}\right)_{2} \mathrm{SO}_{4}$ (s) plus letovicite. The dashed line shows the amounts of $\left(\mathrm{NH}_{4}\right)_{2} \mathrm{SO}_{4}$ (s) predicted if letovicite is prevented from forming.

each species in the gas phase plus the aggregates of bins 615. As noted earlier, this simplification is necessary because AIM is not currently capable of representing multiple size fractions with different chemical compositions. The effect of bulking the particulate phase for the AIM calculations may somewhat moderate the effects of differences noted above for $\mathrm{HNO}_{3}$ and $\mathrm{NH}_{3}$, because most of the aerosol mass resides in the bins containing the smaller aerosols, whereas the differences in predicted partial pressures are greatest for the less acid aerosols in the larger size range.

Total particulate water is shown in Fig. 11, and the total amounts of solids predicted by AIM in Fig. 12. Calculations with $A I M$ were carried out for two cases: (i) all potential solids were allowed to form and, (ii) only $\left(\mathrm{NH}_{4}\right)_{2} \mathrm{SO}_{4(\mathrm{~s})}$ was able to form. The results, in the first case, are similar to those obtained for the calculation using the contents of the individual size bins, and shown earlier in Fig. 7. However, in this calculation for the aggregate composition the double salt does not form. The results for case (ii) more closely match the water-limited prediction of the UCD-CACM model (for which the aerosol does not dry out), and this case is used in some other comparisons below.

Amounts of gas phase $\mathrm{HNO}_{3}$ and $\mathrm{NH}_{3}$ predicted by the models are compared in Fig. 13. There are two separate factors that can lead to differences: the two activity coefficient models yielding different predictions of $\mathrm{pHNO}_{3}$ and $\mathrm{pNH}_{3}$ (in part due to the lack of dissociation equilibrium as described above), and disequilibrium between the two phases in the UCD-CACM model calculations caused by dynamic 
factors. The results shown in Fig. 10 for 08:00 a.m. indicate equilibrium for $\mathrm{HNO}_{3}$ (which has the higher vapour pressure), but that the amount of $\mathrm{NH}_{3}$ in the vapour phase differs from the equilibrium value by up to a factor of about 3. These are typical of much of the diurnal cycle. Predicted equilibrium $\mathrm{pNH}_{3}$ from the UCD-CACM model are shown in Fig. 13 (as vertical bars) to assess this effect.

Despite the activity coefficient model differences, the amounts of gas phase $\mathrm{HNO}_{3}$ predicted by the two models agree well over the whole cycle, and those for $\mathrm{NH}_{3}$ for the period after 09:00 a.m. and during the afternoon when $\mathrm{pNH}_{3}$ is greater than about $1 \times 10^{-8} \mathrm{~atm}$. It is only for the more acidic system in the early part of the cycle, for which $\mathrm{pNH}_{3}$ is below $10^{-10} \mathrm{~atm}$, that there are significant differences between the models. There are two reasons for this: first, in the morning period, before the large increase in total ammonia in the system, the aerosol is acidic and AIM calculations show that about $30 \%$ to $65 \%$ of total dissolved $\mathrm{SO}_{4}^{2-}$ in the aerosol exists as $\mathrm{HSO}_{4}^{-}$. The equilibrium $\mathrm{HSO}_{4(\mathrm{aq})}^{-} \leftrightarrow \mathrm{H}_{(\mathrm{aq})}^{+}+\mathrm{SO}_{4(\mathrm{aq})}^{2-}$, which is not treated in the UCD-CACM model, is therefore a major influence on $\mathrm{H}_{(\mathrm{aq})}^{+}$concentration and activity in this part of the diurnal cycle. The second reason is the relative amounts of total gas and aqueous phase ammonia: at 08:00 a.m. the moles of $\mathrm{NH}_{3}$ in the gas phase are just $1 \%$ of the total ammonia $\left(\mathrm{NH}_{3(\mathrm{aq})}+\mathrm{NH}_{4(\mathrm{aq})}^{+}\right)$in the aerosol. Consequently differences in the equilibrium $\mathrm{pNH}_{3}$ calculated by the activity coefficient models will be reflected in the amounts of $\mathrm{NH}_{3}$ present in the gas phase. However, these amounts are so small before 02:00 p.m. in the diurnal cycle - below about $10^{-10} \mathrm{~atm}$ predicted by both models - that the differences are not significant.

In contrast, during the late afternoon the total ammonia in the aerosol liquid phase (calculated using AIM) is only $1 / 6$ of the amount of gas phase $\mathrm{NH}_{3}$, and a significant amount of ammonia is also present as $\left(\mathrm{NH}_{4}\right)_{2} \mathrm{SO}_{4(\mathrm{~s})}$. The aerosol is also much less acidic, with the amount of $\mathrm{HSO}_{4(\mathrm{aq})}^{-}$negligible compared to $\mathrm{SO}_{4(\mathrm{aq})}^{2-}$. Under these conditions the differences between the equilibrium partial pressures of $\mathrm{NH}_{3}$ over the aerosol calculated by the two models are much smaller, and have only a minor effect on the amount of gaseous $\mathrm{NH}_{3}$.

\subsubsection{Organic component behaviour}

Using AIM, we have recalculated the liquid/liquid equilibrium of the ten SOA surrogate species and their equilibrium partial pressures for the aerosol compositions in each size bin (the sums of the amounts of all species in the aqueous and hydrophobic phases) generated by the UCD-CACM model. The relevant differences between the two models for these compounds are: (i) in the UCD-CACM model the dissociation of the organic acid species contributes to total dissolved $\mathrm{H}^{+}$, but this change does not affect the calculation of the inorganic equilibria (Pun et al., 2002); (ii) the activity coefficients of the organic acid anions are assumed to be the same

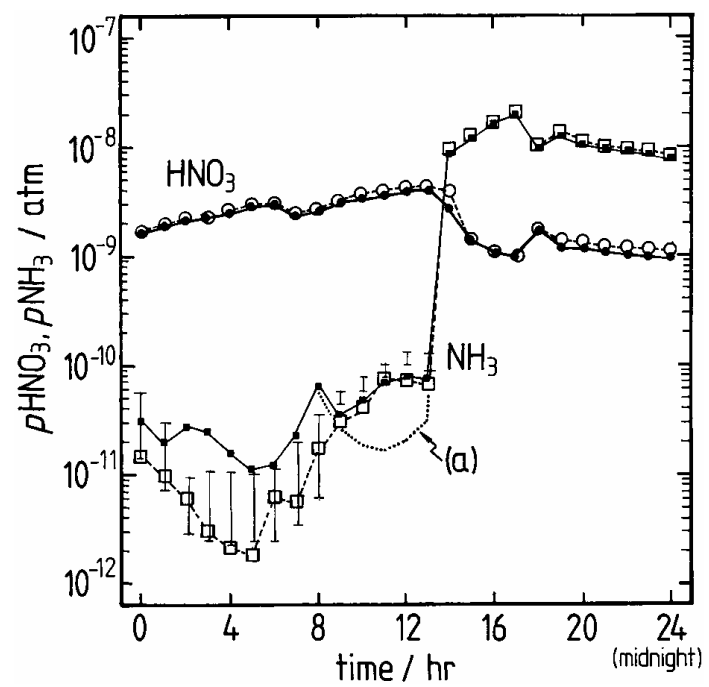

Fig. 13. Calculated partial pressures of $\mathrm{HNO}_{3}$ and $\mathrm{NH}_{3}$ in the gas phase, over the diurnal cycle. Open circle and dashed line amounts of $\mathrm{HNO}_{3}$ from the UCD-CACM model result; dot and solid line - amounts of $\mathrm{HNO}_{3}$ from the AIM gas/aerosol equilibrium calculation. Open square and dashed line - amounts of $\mathrm{NH}_{3}$ from the UCD-CACM model result; solid square and line - amounts of $\mathrm{NH}_{3}$ from the $A I M$ gas/aerosol equilibrium calculation. The dotted line (a) indicates the $A I M$ result for $\mathrm{pNH}_{3}$ where only the solid $\left(\mathrm{NH}_{4}\right)_{2} \mathrm{SO}_{4 \text { (s) }}$ can form. (Except for the period 08:00 a.m. to 01:00 p.m. this differs negligibly from the main result shown). The vertical lines from midnight to 01:00 p.m. show the range of equilibrium partial pressures over size bins 8-16 (UCD-CACM model) to indicate the degree of disequilibrium between the gas phase and larger aerosol size bins. After 01:00 p.m., and for $\mathrm{HNO}_{3}$ at all times, the range is small and close to the actual partial pressure and is not shown.

as those of the undissociated molecule in the UCD-CACM model whereas in AIM they are assigned interaction parameters with cations that are the same as those for $\mathrm{HSO}_{4}^{-}$(for singly charged anions) or $\mathrm{SO}_{4}^{2-}$ (for doubly charged anions); (iii) the differences in the total amounts of aerosol water that the models predict - which can be large for situations where different solids are present - affect the species amounts in the aqueous fraction. The calculations in this section were carried out to establish the significance of these differences, and to verify the UCD-CACM model.

We first consider how the surrogate species distribute between the two liquid phases. Figure 14 shows the calculated fractions of total particulate A1-5 and B1-5 present in the aqueous phase. Results from the UCD-CACM model show that particulate A1-5 exist almost entirely in the aqueous phase, except for A5 (approx. 96\% aqueous) in the later part of the cycle. Calculations using AIM, Fig. 14b, show similar partitioning except at the beginning and middle of the cycle where AIM predicts smaller amounts of aerosol water than the UCD-CACM model which reaches its lower limit. At 

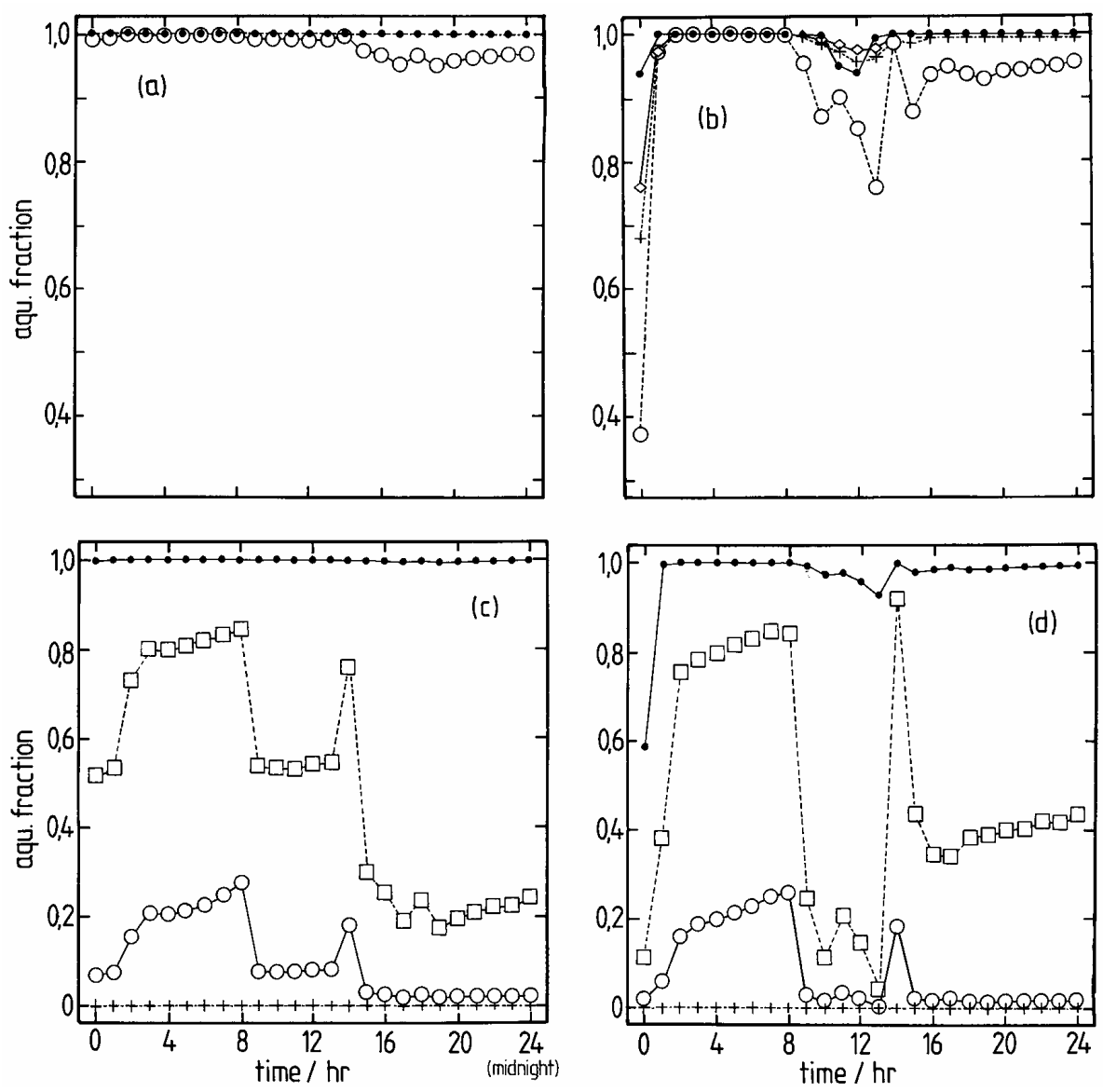

Fig. 14. The fraction of total particulate A1-5 and B1-5 present in the aqueous phase of the aerosol, over the diurnal cycle. (a) UCD-CACM model result: open circle and solid line - A5; dot and dashed line - A1-4. (b) AIM result: dot and solid line - A1; diamond and solid line A2 and A4; plus and dashed line - A3; open circle and dashed line - A5. (c) UCD-CACM model result: dot and solid line - B1; open square and dashed line - B2; plus and dashed line - B3 and B4; open circle and solid line B5. (d) AIM result: lines and symbols same as in (c).

low RH where the aerosol dries out, most of the total amount of A1-5 in the air parcel would be expected to be in the gas phase. Partitioning results for surrogates B1-5 show that particulate $\mathrm{B} 1$ resides almost entirely in the aqueous phase, B3 and B4 in the hydrophobic phase, and particulate B2 and B5 are present in significant amounts in both phases. Again, the differences between the aqueous fractions predicted by both models and shown in Figs. 14c, d reflect the different amounts of aerosol water, which are shown in Fig. 7.

Next, results for a single time point at which both models predict similar amounts of liquid water, and no solids, were examined. Table 1 shows the total amounts, and degrees of dissociation in the aqueous phase, for all size bins at 08:00 a.m. The reason that surrogates A1-5 reside almost entirely in the aqueous phase is partly because their activity coefficients in the hydrophobic phase are of the order of 500 to 5000 (not shown in the table), and partly because the total amounts of water solvent in each of the aerosol size bins are about two orders of magnitude greater than the sum of the primary hydrocarbons P1-8 that act as the solvent in the hy- drophobic phase. For this case the results of the two models are essentially the same for partitioning of A1-5 between the two aerosol phases.

Some differences are found for compounds B1-5. The total amounts of B1-5 in the aqueous phase calculated by the two models are compared as ratios in Fig. 15 at 08:00 a.m. for all size bins. The small differences from unity $(<3 \%)$ for B3-5 reflect differences in the total amounts of aerosol water predicted by the two models at this RH and can be neglected. For B2, for which AIM predicts up to $19.5 \%$ dissociation in bin 15 (see Table 1), the difference in the ratio is up to $9 \%$. It is greatest in the least acidic size bins for which the degree of dissociation, $\alpha$ in Table 1, is highest. In neutral or alkaline systems we would expect the deviations from unity to be larger still. They are primarily due to the different assumptions made regarding the organic anion activity coefficients.

Surrogates A1, A2, A4, B1 and B2 dissociate in aqueous solution. At 08:00 a.m. the undissociated fractions exceed $99 \%$ of the totals in the aqueous phase in the UCDCACM model, except for A1 which is $92 \%$. AIM predicts 
Table 1. Total Amounts $\left(\mu \mathrm{mol} \mathrm{m}{ }^{-3}\right)$ of Anthropogenic and Biogenic Surrogates in the Aerosol at 08:00 a.m., and their Degrees of Dissocation $(\alpha)$ in the Aqueous Phase Calculated Using AIM.

\begin{tabular}{lllllllll}
\hline Bin & $\mathrm{H}_{2} \mathrm{O}$ & $\mathrm{B} 1_{(\mathrm{aq})}$ & $\alpha$ & $\mathrm{B} 2(\mathrm{aq})$ & $\alpha$ & $\mathrm{B}_{(\mathrm{aq})}$ & $\mathrm{B}_{(\mathrm{aq})}$ & $\mathrm{B}_{(\mathrm{aq})}$ \\
\hline 6 & $8.81 \mathrm{E}-02$ & $2.12 \mathrm{E}-07$ & 0.0002 & $4.49 \mathrm{E}-09$ & 0.0008 & $3.09 \mathrm{E}-12$ & $1.02 \mathrm{E}-10$ & $3.69 \mathrm{E}-12$ \\
7 & $8.98 \mathrm{E}-02$ & $2.17 \mathrm{E}-07$ & 0.0007 & $4.53 \mathrm{E}-09$ & 0.0028 & $3.02 \mathrm{E}-12$ & $9.99 \mathrm{E}-11$ & $3.63 \mathrm{E}-12$ \\
8 & $1.44 \mathrm{E}-01$ & $3.43 \mathrm{E}-07$ & 0.0038 & $7.32 \mathrm{E}-09$ & 0.0162 & $4.88 \mathrm{E}-12$ & $1.61 \mathrm{E}-10$ & $5.89 \mathrm{E}-12$ \\
9 & $1.30 \mathrm{E}-01$ & $3.00 \mathrm{E}-07$ & 0.0062 & $6.60 \mathrm{E}-09$ & 0.0262 & $4.41 \mathrm{E}-12$ & $1.46 \mathrm{E}-10$ & $5.34 \mathrm{E}-12$ \\
10 & $9.12 \mathrm{E}-02$ & $1.98 \mathrm{E}-07$ & 0.0088 & $4.63 \mathrm{E}-09$ & 0.0368 & $3.10 \mathrm{E}-12$ & $1.03 \mathrm{E}-10$ & $3.74 \mathrm{E}-12$ \\
11 & $4.89 \mathrm{E}-02$ & $9.45 \mathrm{E}-08$ & 0.0265 & $2.53 \mathrm{E}-09$ & 0.1050 & $1.69 \mathrm{E}-12$ & $5.61 \mathrm{E}-11$ & $2.03 \mathrm{E}-12$ \\
12 & $2.79 \mathrm{E}-02$ & $4.29 \mathrm{E}-08$ & 0.0420 & $1.43 \mathrm{E}-09$ & 0.1590 & $9.67 \mathrm{E}-13$ & $3.20 \mathrm{E}-11$ & $1.16 \mathrm{E}-12$ \\
13 & $1.74 \mathrm{E}-02$ & $2.36 \mathrm{E}-08$ & 0.0428 & $9.20 \mathrm{E}-10$ & 0.1618 & $6.01 \mathrm{E}-13$ & $1.97 \mathrm{E}-11$ & $7.20 \mathrm{E}-13$ \\
14 & $1.04 \mathrm{E}-02$ & $1.16 \mathrm{E}-08$ & 0.0472 & $5.70 \mathrm{E}-10$ & 0.1760 & $3.61 \mathrm{E}-13$ & $1.11 \mathrm{E}-11$ & $4.33 \mathrm{E}-13$ \\
15 & $4.57 \mathrm{E}-03$ & $2.97 \mathrm{E}-09$ & 0.0531 & $2.52 \mathrm{E}-10$ & 0.1946 & $1.58 \mathrm{E}-13$ & $4.19 \mathrm{E}-12$ & $1.89 \mathrm{E}-13$ \\
\hline
\end{tabular}

\begin{tabular}{lllllllll}
\hline Bin & A1 $(\mathrm{aq})$ & $\alpha$ & A2 $(\mathrm{aq})$ & $\alpha$ & $\mathrm{A}_{(\mathrm{aq})}$ & $\mathrm{A}_{(\mathrm{aq})}$ & $\alpha$ & $\mathrm{A}_{(\mathrm{aq})}$ \\
\hline 6 & $1.02 \mathrm{E}-08$ & 0.0061 & $3.82 \mathrm{E}-06$ & 0.0000 & $8.17 \mathrm{E}-09$ & $2.64 \mathrm{E}-08$ & 0.0001 & $6.11 \mathrm{E}-08$ \\
7 & $1.04 \mathrm{E}-08$ & 0.0200 & $3.29 \mathrm{E}-06$ & 0.0000 & $8.35 \mathrm{E}-09$ & $2.69 \mathrm{E}-08$ & 0.0003 & $6.24 \mathrm{E}-08$ \\
8 & $1.68 \mathrm{E}-08$ & 0.1072 & $3.59 \mathrm{E}-06$ & 0.0001 & $1.35 \mathrm{E}-08$ & $4.22 \mathrm{E}-08$ & 0.0015 & $1.01 \mathrm{E}-07$ \\
9 & $1.51 \mathrm{E}-08$ & 0.1648 & $2.42 \mathrm{E}-06$ & 0.0001 & $1.21 \mathrm{E}-08$ & $3.69 \mathrm{E}-08$ & 0.0024 & $9.05 \mathrm{E}-08$ \\
10 & $1.06 \mathrm{E}-08$ & 0.2195 & $1.18 \mathrm{E}-06$ & 0.0002 & $8.50 \mathrm{E}-09$ & $2.48 \mathrm{E}-08$ & 0.0034 & $6.35 \mathrm{E}-08$ \\
11 & $5.68 \mathrm{E}-09$ & 0.4709 & $3.95 \mathrm{E}-07$ & 0.0006 & $4.57 \mathrm{E}-09$ & $1.17 \mathrm{E}-08$ & 0.0103 & $3.41 \mathrm{E}-08$ \\
12 & $3.30 \mathrm{E}-09$ & 0.5952 & $1.22 \mathrm{E}-07$ & 0.0010 & $2.60 \mathrm{E}-09$ & $5.23 \mathrm{E}-09$ & 0.0165 & $1.94 \mathrm{E}-08$ \\
13 & $2.06 \mathrm{E}-09$ & 0.6005 & $5.76 \mathrm{E}-08$ & 0.0010 & $1.61 \mathrm{E}-09$ & $2.65 \mathrm{E}-09$ & 0.0169 & $1.21 \mathrm{E}-08$ \\
14 & $1.24 \mathrm{E}-09$ & 0.6261 & $2.37 \mathrm{E}-08$ & 0.0011 & $9.56 \mathrm{E}-10$ & $1.13 \mathrm{E}-09$ & 0.0186 & $7.26 \mathrm{E}-09$ \\
15 & $5.03 \mathrm{E}-10$ & 0.6567 & $4.86 \mathrm{E}-09$ & 0.0012 & $3.96 \mathrm{E}-10$ & $2.63 \mathrm{E}-10$ & 0.0210 & $3.05 \mathrm{E}-09$ \\
\hline
\end{tabular}

\begin{tabular}{|c|c|c|c|c|c|c|}
\hline Bin & $\Sigma$ P1-8 & B $1_{\text {(org) }}$ & B2 (org) & B3 ${ }_{\text {(org) }}$ & B4 ${ }_{\text {(org) }}$ & $\mathrm{B}_{\text {(org) }}$ \\
\hline 6 & $1.11 \mathrm{E}-3$ & $1.71 \mathrm{E}-10$ & 2.38E-09 & 2.19E-08 & $1.08 \mathrm{E}-06$ & $3.21 \mathrm{E}-11$ \\
\hline 7 & $6.54 \mathrm{E}-4$ & $9.95 \mathrm{E}-11$ & $1.40 \mathrm{E}-09$ & $1.25 \mathrm{E}-08$ & $5.99 \mathrm{E}-07$ & $1.79 \mathrm{E}-11$ \\
\hline 8 & $3.63 \mathrm{E}-4$ & $4.59 \mathrm{E}-11$ & 7.12E-10 & $6.45 \mathrm{E}-09$ & $2.84 \mathrm{E}-07$ & $8.55 \mathrm{E}-12$ \\
\hline 9 & $1.81 \mathrm{E}-4$ & $1.88 \mathrm{E}-11$ & $3.25 \mathrm{E}-10$ & $3.00 \mathrm{E}-09$ & $1.21 \mathrm{E}-07$ & $3.66 \mathrm{E}-12$ \\
\hline 10 & $2.30 \mathrm{E}-4$ & $2.64 \mathrm{E}-11$ & $4.40 \mathrm{E}-10$ & 4.10E-09 & $1.81 \mathrm{E}-07$ & $5.43 \mathrm{E}-12$ \\
\hline 11 & $2.68 \mathrm{E}-4$ & $2.91 \mathrm{E}-11$ & $4.99 \mathrm{E}-10$ & 4.99E-09 & $2.32 \mathrm{E}-07$ & $6.91 \mathrm{E}-12$ \\
\hline 12 & $5.30 \mathrm{E}-5$ & $2.99 \mathrm{E}-12$ & 7.61E-11 & $8.24 \mathrm{E}-10$ & $3.08 \mathrm{E}-08$ & $9.21 \mathrm{E}-13$ \\
\hline 13 & $1.74 \mathrm{E}-4$ & $8.70 \mathrm{E}-12$ & $2.58 \mathrm{E}-10$ & 2.71E-09 & $1.00 \mathrm{E}-07$ & $3.03 \mathrm{E}-12$ \\
\hline 14 & $2.09 \mathrm{E}-4$ & $8.47 \mathrm{E}-12$ & $3.14 \mathrm{E}-10$ & $3.25 \mathrm{E}-09$ & $1.13 \mathrm{E}-07$ & $3.64 \mathrm{E}-12$ \\
\hline 15 & $9.17 \mathrm{E}-5$ & $2.15 \mathrm{E}-12$ & $1.36 \mathrm{E}-10$ & $1.42 \mathrm{E}-09$ & 4.27E-08 & $1.59 \mathrm{E}-12$ \\
\hline
\end{tabular}

\begin{tabular}{llllll}
\hline Bin & $\mathrm{A}_{(\text {org })}$ & $\mathrm{A}_{(\text {org })}$ & $\mathrm{A} 3_{(\text {org })}$ & $\mathrm{A}_{(\text {org })}$ & $\mathrm{A}_{(\text {org })}$ \\
\hline 6 & $3.41 \mathrm{E}-13$ & $5.82 \mathrm{E}-10$ & $4.09 \mathrm{E}-12$ & $8.42 \mathrm{E}-12$ & $3.78 \mathrm{E}-10$ \\
7 & $2.02 \mathrm{E}-13$ & $2.89 \mathrm{E}-10$ & $2.37 \mathrm{E}-12$ & $4.84 \mathrm{E}-12$ & $2.18 \mathrm{E}-10$ \\
8 & $9.49 \mathrm{E}-14$ & $9.69 \mathrm{E}-11$ & $1.11 \mathrm{E}-12$ & $2.17 \mathrm{E}-12$ & $1.01 \mathrm{E}-10$ \\
9 & $4.13 \mathrm{E}-14$ & $3.23 \mathrm{E}-11$ & $4.71 \mathrm{E}-13$ & $8.83 \mathrm{E}-13$ & $4.25 \mathrm{E}-11$ \\
10 & $5.23 \mathrm{E}-14$ & $3.17 \mathrm{E}-11$ & $7.04 \mathrm{E}-13$ & $1.28 \mathrm{E}-12$ & $6.41 \mathrm{E}-11$ \\
11 & $4.21 \mathrm{E}-14$ & $2.42 \mathrm{E}-11$ & $8.91 \mathrm{E}-13$ & $1.43 \mathrm{E}-12$ & $8.17 \mathrm{E}-11$ \\
12 & $5.50 \mathrm{E}-15$ & $1.97 \mathrm{E}-12$ & $1.16 \mathrm{E}-13$ & $1.40 \mathrm{E}-13$ & $1.04 \mathrm{E}-11$ \\
13 & $1.79 \mathrm{E}-14$ & $4.94 \mathrm{E}-12$ & $3.81 \mathrm{E}-13$ & $3.76 \mathrm{E}-13$ & $3.44 \mathrm{E}-11$ \\
14 & $2.01 \mathrm{E}-14$ & $4.05 \mathrm{E}-12$ & $4.52 \mathrm{E}-13$ & $3.20 \mathrm{E}-13$ & $4.12 \mathrm{E}-11$ \\
15 & $7.50 \mathrm{E}-12$ & $8.32 \mathrm{E}-13$ & $1.87 \mathrm{E}-13$ & $7.42 \mathrm{E}-14$ & $1.73 \mathrm{E}-11$ \\
\hline
\end{tabular}




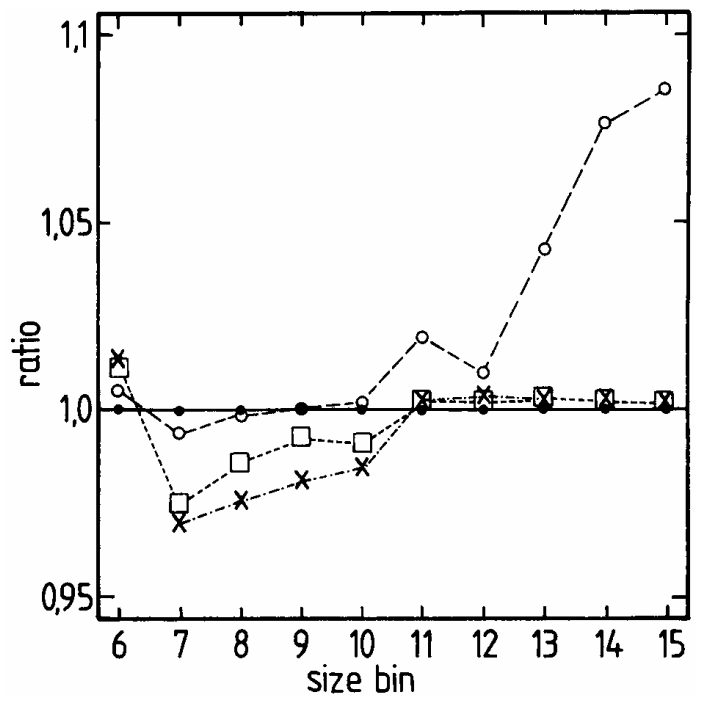

Fig. 15. The ratios of the amounts of surrogate species B1-5 in the aqueous phase at 08:00 a.m., calculated using the UCD-CACM model and AIM (for total aerosol amounts of all species except water fixed to values from the UCD-CACM model). The ratio is equal to AIM/UCD-CACM. Dot and solid line - B1; open circle and dashed line - B2; cross and dash-dot line - B3 and B4; square and dashed line - B5.

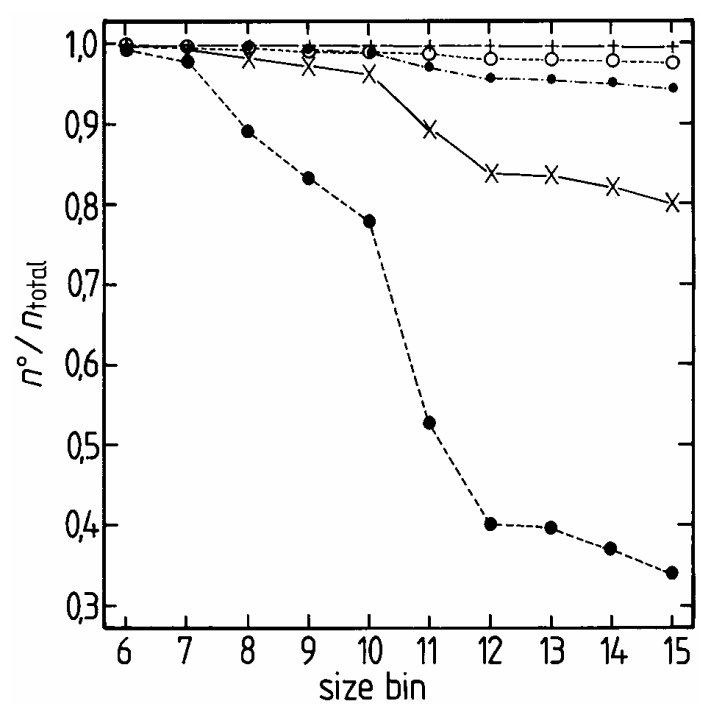

Fig. 16. The fractions of the total aqueous amounts $\left(n_{\text {total }}\right)$ of the water soluble surrogate species A1-5 and B1-2 calculated by AIM to be in the undissociated form $\left(n^{o}\right)$ at 08:00 a.m. A value of $n^{o} / n_{\text {total }}$ of unity corresponds to zero dissociation. Solid circle and dashed line - A1; plus and solid line - A2; open circle and dashed line A4; dot and dash-dot line - B1; cross and solid line - B2.

much greater degrees of dissociation for most of these compounds especially in the less acidic size bins, as can be seen in Fig. 16. The greater degree of dissociation predicted by AIM for A1 in size bin 15 is due to, first, the formation

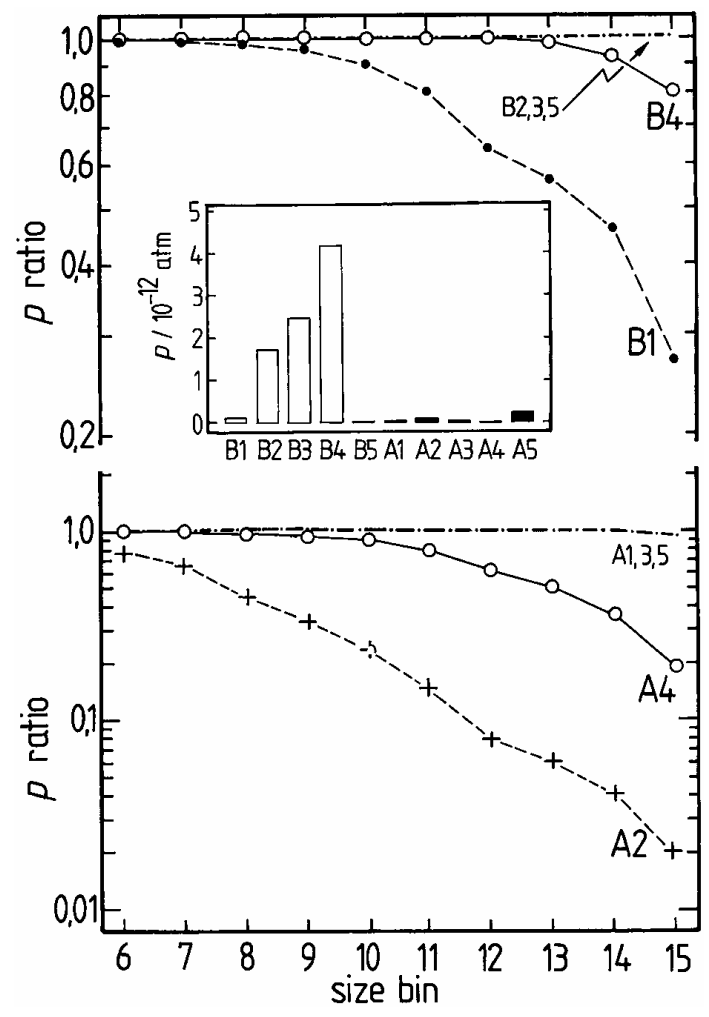

Fig. 17. Ratios of the equilibrium partial pressures of organic surrogate species for each size bin at 08:00 a.m. to the actual amounts present in the gas phase in the UCD-CACM model result. (The equilibrium partial pressures were also calculated using the UCDCACM model.) Values of less than unity correspond to concentrations of the surrogates in the aerosol phase less than those required for equilibrium with the gas phase. Upper plot: surrogates B1-5, as indicated, with the actual vapour pressures of all the surrogates shown in the inset. Lower plot: surrogates A1-5.

of $\mathrm{HSO}_{4}^{-}$leading to a free $\mathrm{H}^{+}$molality of 0.168 compared to a total (including $\mathrm{HSO}_{4}^{-}$) of 0.629 ; second, a value of $\gamma \mathrm{H}^{+}$of 0.29 compared to an assumed value of 1.0 in the UCD-CACM model. Consequently the activity of $\mathrm{H}^{+}$in the dissociation calculation (in AIM) is much lower than in the UCD-CACM model. However, compared to other model uncertainties, not least the values of the dissociation constants themselves, the effect on SOA yield is minor. It should also be remembered that, in the model, partitioning is controlled by mass transfer which is calculated at each time step, and aerosols - particularly the bins representing the larger sizes can be out of equilibrium with the gas phase. Ratios of equilibrium partial pressures to actual values in the gas phase, from the UCD-CACM model for 08:00 a.m., are compared in Fig. 17. The aerosol contains much less of B1, A2, and A4 (by a factor of $\times 50$ for A2) than required for equilibrium with the gas phase. The air parcel is still over the ocean at 08:00 a.m., and so the gas phase is interacting with the marine background aerosol. The amount of surface area 

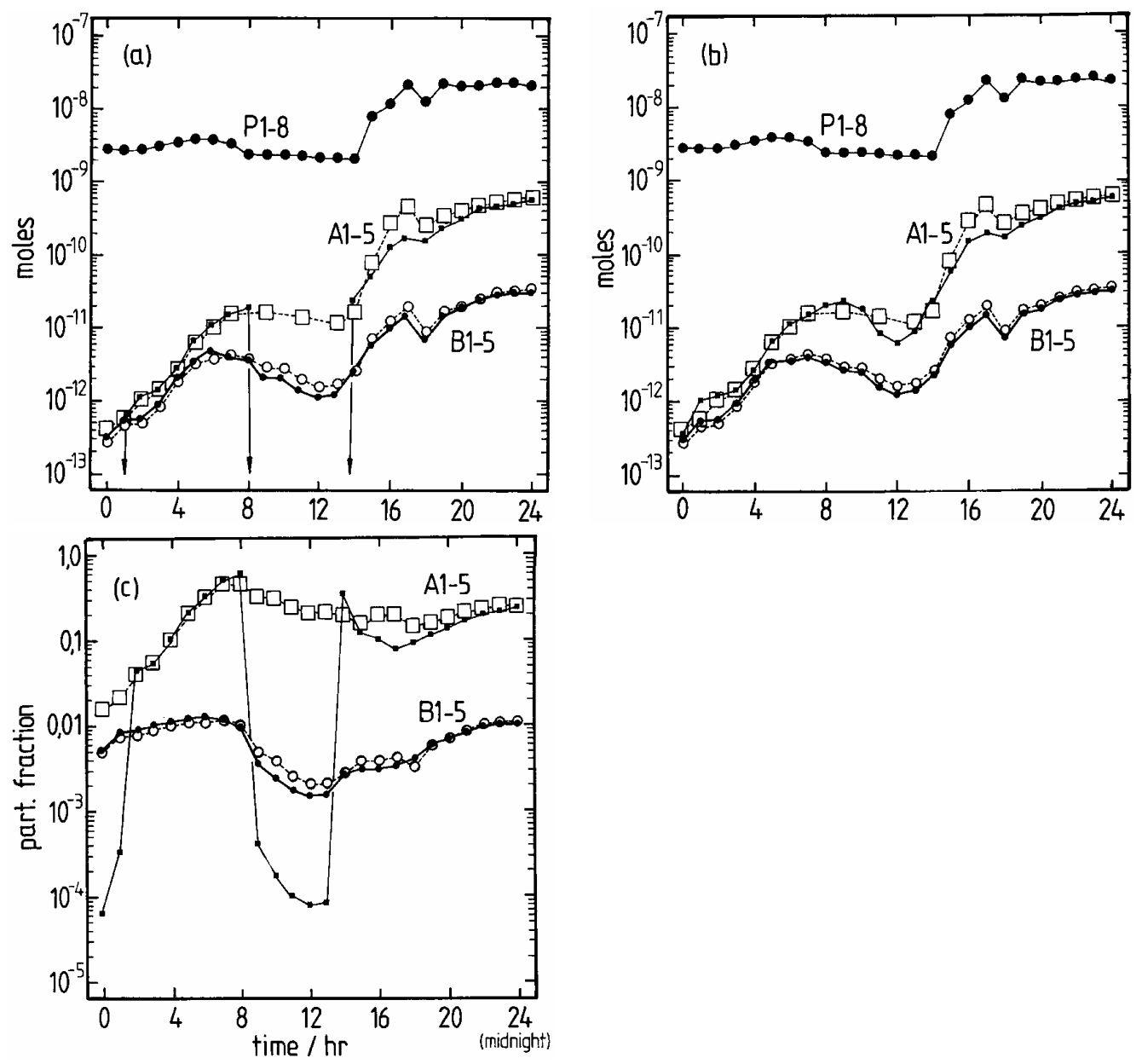

Fig. 18. Calculated total amounts $\left(\mathrm{mol} \mathrm{m}^{-3}\right)$ of aerosol phase surrogate organic compounds over the diurnal cycle. Open squares and open circles with dashed lines - UCD-CACM model; solid symbols and solid lines - AIM calculations. Values for primary compounds P1-8 are the same for both models. (a) All solids are allowed to form in the AIM calculation, resulting in the amounts of particulate A1-5 going to negligible values for periods for which the aerosol is predicted to be dry (contain no water). (b) Only $\left(\mathrm{NH}_{4}\right)_{2} \mathrm{SO}_{4(\mathrm{~s})}$ is allowed to form in the AIM calculation, and the aerosol contains liquid water throughout the cycle. (c) Particulate fractions of total A1-5, and B1-5. In the AIM calculation all solids are allowed to form, corresponding to the result in plot (a).

available to facilitate gas-to-particle conversion is relatively small, and temperatures low. Wexler and Seinfeld (1991) showed that these conditions promote non-equilibrium behavior in a system involving condensation of inorganic acids and bases. The present case involves condensation of organic molecules with even smaller diffusion coefficients. It is reasonable that equilibrium predictions for gas-to-particle conversion differ from the results of the more realistic dynamic exchange calculation used in the UCD-CACM model.

Next, we compare AIM calculations of full gas/aerosol equilibrium with the results of the UCD-CACM model over the complete diurnal cycle, to assess the practical effect of the model differences discussed above. Total moles of particulate primary and secondary organic material are shown in Fig. 18. Primaries P1-8 are the same for both models as these species are defined as existing entirely in the particle phase. Totals for surrogates A1-5 and B1-5 differ most between about 08:00 a.m. and 02:00 p.m. where AIM predicts the total drying out of the aqueous aerosol phase. The second plot in the figure shows AIM predictions for a set of simulations in which only $\left(\mathrm{NH}_{4}\right)_{2} \mathrm{SO}_{4(\mathrm{~s})}$ is able to form, and confirm the requirement for aerosol water for organic surrogate species A1-5 to occur in the aerosol. The fractions of total A1-5 and B1-5 present in the aerosol phase are shown in Fig. 18c. From 08:00 a.m. onwards, $20 \%$ or more of total A1-5 occurs in the aerosol phase (mostly A2, because of its low vapour pressure), but less than $1 \%$ of total B1-5.

Several conclusions can be drawn from the comparisons here: first, differences between the amounts of liquid phase water predicted by the models at low $\mathrm{RH}$, related to the 


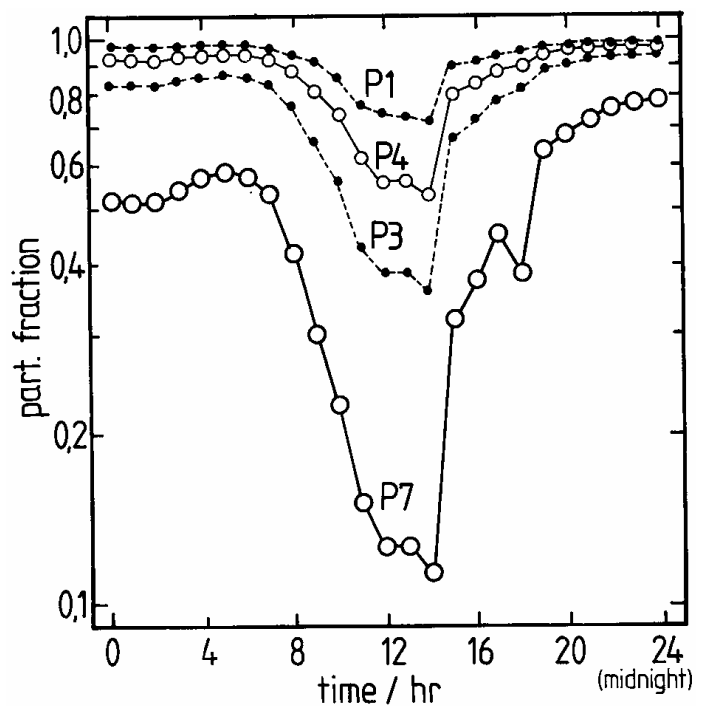

Fig. 19. Calculated fractions of each primary surrogate compound present in the aerosol phase for gas/aerosol equilibrium calculations in which the vapour pressures listed in the first line of Table 5 of Paper 2 are assigned. More than 99\% of P2 and P6 are predicted to occur in the vapour phase (not shown), P8 is assigned entirely to the aerosol phase, as noted in the text, and there is no P5 present in the system.

formation of solids (and the positive lower bound on aerosol water in the UCD-CACM model), strongly influence the aerosol yield of those surrogates that are water soluble and do not significantly partition into the hydrophobic phase. Second, the simplifications introduced into the UCD-CACM model treatment of the dissociation of the organic solutes do not have a major effect on overall gas/aerosol partitioning in the example studied here, although this might not be the case for neutral or alkaline aerosol systems. Third, dissociation is unlikely to be estimated satisfactorily without an explicit treatment of the sulphate/bisulphate equilibrium, and calculated (rather than assumed) activity coefficients of $\mathrm{H}_{(\mathrm{aq})}^{+}$and organic anions. In the current UCD-CACM model, organic acid dissociation could probably be omitted. Finally, it has been shown earlier, in Fig. 2, that many of the surrogate semivolatile compounds partition almost entirely into one aerosol phase. This offers opportunities for simplifying and increasing the efficiency of gas/aerosol partitioning calculations, by eliminating the liquid/liquid equilibrium calculation for such compounds.

\subsection{Further atmospheric simulations}

In this section gas/aerosol partitioning of the primary surrogate organic compounds, the influence of the UNIFAC activity coefficients on gas/aerosol partitioning of the semivolatile species, and the effects of variations in $p^{o}$ of these compounds, are briefly examined. Both AIM and UCDCACM model simulations are used.

\subsubsection{Partitioning of primary organic compounds}

Gas/aerosol equilibrium calculations for the diurnal cycle have been repeated, allowing primary surrogate compounds P1-7 to partition into the gas phase based upon the vapour pressures and enthalpies of vaporisation listed for the model of Nannoolal (2007) in Table 5 of Paper 2. This model appears to be one of the most accurate of those tested. Although the predicted vapour pressure for P8 is quite high, it has been confined to the aerosol phase as it represents the broad class of mainly hydrocarbon, involatile, material that is found in most aerosols. The results are plotted in Fig. 19 as the fraction of the total amount of each surrogate compound present in the aerosol phase. There is significant variation over the course of the day. The decrease in the particulate fractions around the middle of the day is partly a response to increased temperature, but mainly to the amounts of P8 available as a solvent. (Fig. 18 shows that these increase by about an order of magnitude from 02:00 p.m. to 05:00 p.m. due to anthropogenic emissions.) Less than $1 \%$ of the surrogates P2 (primary organic di-acids) and P6 (aromatics) are predicted to be in the aerosol phase at all times. For P2 this does not seem reasonable, both because di-acids with a larger number of carbon atoms than succinic acid (which is the selected surrogate) will have lower vapour pressures, and because the diacids are water soluble. These results - that the primary organic compounds will partition between the gas and aerosol phases - are at least qualitatively consistent with the work of Robinson et al. (2007), who argue that most primary organic particulate emissions are semi-volatile.

\subsubsection{The influence of non-ideality in the liquid phase}

In Sect. 3.3 of Paper 2 the variation of the partitioning of water soluble compounds as a function of their sub-cooled vapour pressures was examined. It was assumed that activity coefficients in the liquid phase were unity. In the UCDCACM model UNIFAC is used to obtain estimates of activity coefficients for water plus surrogates A1-5 and B1-5 in the aqueous phase, and for the surrogates plus primary organics in the hydrophobic phase. These determine the organic contribution to the total water content of the aerosol which is small, the partitioning of the surrogates between aqueous and hydrophobic phases, and also influence partitioning between aerosol and gas phases.

What are typical values of the activity coefficients, and to what degree do they control partitioning? Table 2 lists mean, minimum and maximum values of the activity coefficients of each surrogate species, in all size bins, over the full diurnal cycle. For most of these compounds the range of values is not large. For those surrogates occurring mainly in the aqueous phase this can be explained by the fact that, unless inorganic solids form, water will be the major component of the phase. Consequently it is the "interaction" with water that will mainly determine the UNIFAC activity coefficient, and 
Table 2. Ranges of Activity Coefficients of Surrogate Species A1-5, B1-5, in All Size Bins.

\begin{tabular}{llll}
\hline Species & Mean $f_{i}$ & Range & Principal Phase \\
\hline A1 & 1.16 & $1.14-1.18$ & aqueous \\
A2 & 13.2 & $11.3-14.2$ & aqueous \\
A3 & 49.9 & $41.2-54.8$ & aqueous \\
A4 & 38.9 & $32.5-42.1$ & aqueous \\
A5 & 187 & $153-204$ & aqueous \\
B1 & 131 & $105-152$ & aqueous \\
B2 & 2485 & $1906-2792$ & aqueous \\
B3 & 16.7 & $13.9-19.2$ & hydrophobic \\
B4 & 29.2 & $20.3-37.2$ & hydrophobic \\
B5 & 57.1 & $39.7-73.4$ & hydrophobic
\end{tabular}

Notes: values of the mole fraction activity coefficients $f_{i}$ of each surrogate $i$ are for all size bins and for all times over the diurnal cycle. The geometric mean is listed.

not interactions with other organic species that are present at very low mole fractions. Neither model, as already noted, includes interactions between ions and organic solutes.

The mean values of the activity coefficients listed in Table 2 range from about 1.2 to almost 2500. The magnitudes of these activity coefficients, combined with the fact that they are surrogates for real molecules whose actual composition and structure are only approximately known, suggest that the activity coefficients may be a major source of uncertainty in partitioning simulations. To roughly assess this we have carried out calculations using AIM in which Raoult's law $(f=1.0)$ is assumed for the partitioning surrogate species, but at the same time each species is constrained to exist only in the liquid phase (aqueous, or hydrophobic) in which the full model calculations have suggested that it will occur. Thus, A1-5 and B1-2 partition only between the gas and aqueous aerosol phases, while B3-5 partition between the gas and hydrophobic aerosol phases. Primary compounds P1-8 are constrained to the hydrophobic phase, as before. Figure 20 shows the results of a recalculation of SOA formation, assuming Raoult's law as noted above. A comparison of the yields shown in the figure confirms the very large influence of the activity coefficients: in the Raoult's law case the total yield is enhanced by a factor of $\times 5$ or more to $0.5 \mu \mathrm{g} \mathrm{m}^{-3}$ near the end of the cycle when total organic amounts present (gas plus aerosol) are highest. The increase for the B surrogates is greatest, mainly because of the high value of $f \mathrm{~B} 2$ in the standard model result (about $2.5 \times 10^{3}$, see Table 2). These results are in contrast to those of Chen et al. (2006) who compared SOA predictions with and without full activity coefficient calculations in the eastern United States using the model of Griffin and co-workers. In that study, the activity coefficients exerted only a small influence, probably due to the dominance of biogenic SOA in the simulated aerosol.

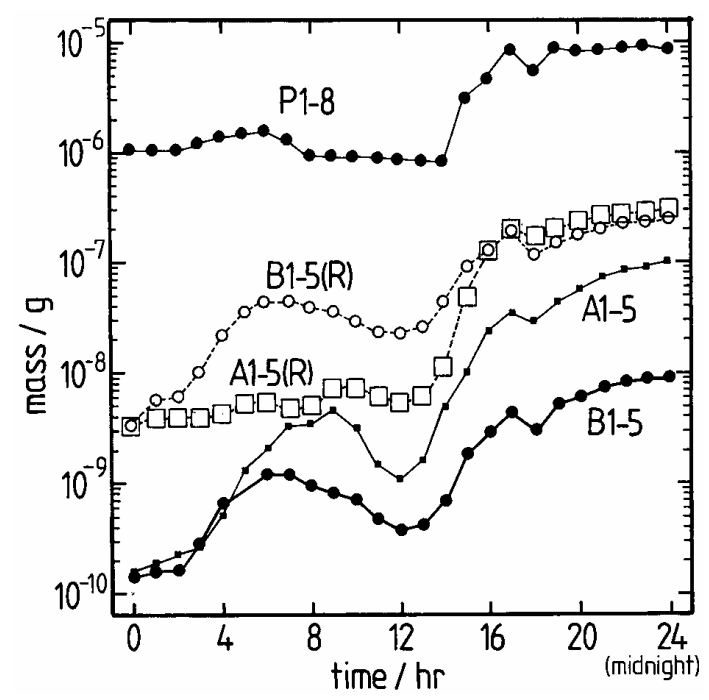

Fig. 20. Total particulate masses of each group of surrogate organic compounds, from the AIM calculation of gas/aerosol equilibrium over the diurnal cycle. Solid symbols and line - A and B surrogate compounds in the standard calculation (also shown in Fig. 17b); open symbols and dashed lines - calculation in which the ten surrogate species A1-5 and B1-5 are assumed to obey Raoult's law "(R)".

The deviations from Raoult's law calculated for the organic surrogate compounds in both phases, and summarised in Table 2, clearly have a significant impact on the calculated SOA yields as well as controlling the partitioning between aqueous and hydrophobic phases. The assignment of surrogate compounds in the UCD-CACM model is generally successful in terms of calculated liquid/liquid phase partitioning - determined by the relative values of $f_{i(\mathrm{aq})}$ and $f_{i(\mathrm{org})}$ in Eq. (1) and the amounts of the solvents water and P1-8 - as earlier shown in Fig. 2. However, we have not compared absolute values of the activity coefficients of the surrogates and the individual compounds they represent. These, combined with $p^{o}$ (discussed at the end of Sect. 3.1.2) drive gas/aerosol partitioning.

\subsubsection{Variations of subcooled vapour pressures $p^{o}$}

The estimates of vapour pressures of the surrogate compounds presented in Tables 5 to 7 of Paper 2 do not, by themselves, establish the uncertainties associated with these vapour pressures but do at least suggest minimum ranges. Based upon the estimated error in the ACD boiling points alone, and neglecting the further uncertainty introduced by the use of the Myrdal and Yalkowsky (1997) equation, the vapour pressures of the ten semi-volatile surrogate species have ranges of uncertainty of about $\times 10$ to $\times 175$ (highest value divided by the lowest). However, this neglects the fact that the surrogates each represent groups of compounds that appear to have very wide ranges of vapour pressure, as shown in Table 8 of Paper 2. 

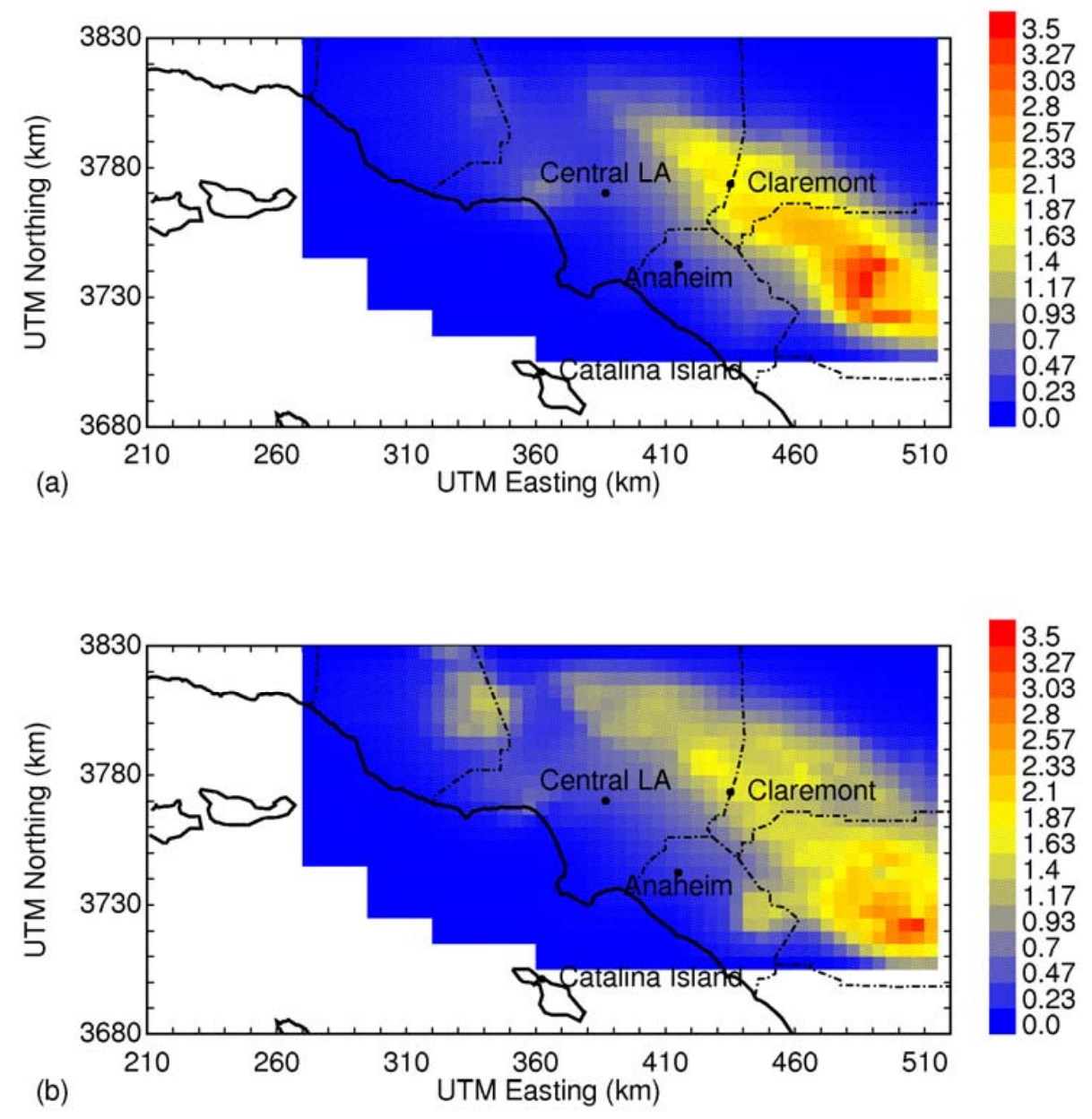

Fig. 21. Predicted $24 \mathrm{~h}$ average concentration of SOA on 9 September 1993. (a) Using vapour pressures calculated using boiling points listed in Table 3 of Paper 2 for the 10 semi-volatile organic species (UCD-CACM method); (b) the increase in SOA concentration obtained when using the same boiling points increased by the uncertainties determined by the ACD boiling point prediction software and listed on the bottom row of Table 3 of Paper 2 .

Together, the results suggest that a comprehensive assessment of the effects of vapour pressure uncertainties on SOA yields should involve two types of analysis: first, atmospheric simulations carried out using ranges of probable vapour pressures of the surrogate compounds, based upon estimates such as those tabulated in Paper 2. Second, processing the results of atmospheric simulations in a similar way to the diurnal cycle but calculating gas/aerosol equilibrium for all the individual compounds represented by the surrogate species. This is possible with models such as AIM, but the work is outside the scope of this study. Here we address the first question, and in Fig. 21a show the predicted 24-h average concentration of SOA in the South Coast Air Basin surrounding Los Angeles on 9 September 1993 using the 3D Eulerian version of the UCD-CACM air quality model (Ying et al., 2007; Kleeman et al., 2007). Base case vapour pressures for the surrogate compounds A1-5 and B1-5 are as listed in Tables 6 and 7 of Paper 2. They differ slightly from those used in previous studies (Kleeman et al., 2007; Ying et al., 2007), because of the correction of errors, but have only a small effect on predicted SOA concentrations. In Fig. $21 \mathrm{~b}$ we show the predicted increase in SOA concentrations that results when lower estimates of the vapour pressures of the semi-volatile surrogate species are used in the calculation. These were obtained by increasing the estimated boiling point of each surrogate compound by the uncertainty given by the ACD prediction software and listed on the bottom row of Table 3 of Paper 2. As shown in Fig. 21b, predicted SOA concentrations come close to doubling in some areas when the lower vapour pressure estimates are used. The greatest increases in predicted SOA concentrations occur in the northern and southern portions of the air basin where biogenic SOA is dominant (Kleeman et al., 2007). Further analysis shows that approximately $2 / 3$ of the increase in predicted SOA concentrations in the southeast corner of the model domain is associated with surrogate species A5 
(2-hydroxy-3-isopropyl-6-keto-heptanal), the components of which are produced from biogenic precursors. The increased SOA concentrations predicted in the vicinity of Claremont are associated with surrogate species B1 (3,5-dimethyl-2nitro-4-hydroxy-benzoic acid), B4 (8-hydroxy-11-nitrooxyhexadecane), A1 (ethanedioic acid), and A2 (2-methyl-5formyl-2,4-hexadiendioic acid). These comprise compounds that derive from anthropogenic PAHs, alkanes, and aromatic hydrocarbons.

\section{Discussion}

The organic fraction of the aerosol in the UCD-CACM model consists of two broad groups of compounds: (i) those of a hydrophobic character and made up of long carbon chains with few polar groups, (ii) a set of smaller oxidation products containing one or more polar groups such as $-\mathrm{OH}$ and $-\mathrm{COOH}$. The definition of the aerosol as containing two liquid phases follows directly from this view. The inorganic and organic components of the aerosol affect each other mainly through the liquid water content, which controls the partitioning of the water soluble semi-volatile compounds, and to a lesser extent through the $\mathrm{pH}$ of the aqueous portion. Further effects can be expected from ion-organic interactions (salting-in or salting-out, which affects activity coefficients), and from reactions in either liquid phase. The latter are not yet treated explicitly in the UCD-CACM model, and the effects of ioninorganic interactions seem likely to be smaller than current uncertainties in the vapour pressures of the semi-volatile organic compounds. Below, we summarise the results of this work, and some of the general implications for the development of air quality models.

\subsection{Organic components}

Major factors affecting the calculated partitioning of organic compounds, excluding the effects of chemical reactions and the dynamics of gas/particle exchange, are: (i) the estimation of subcooled liquid vapour pressures $p^{o}$ which is discussed in Paper 2, (ii) the choice of surrogate compounds and, (iii) their activity coefficients in both aerosol phases. The simulation shown in Fig. 21, for decreased vapour pressures of the semi-volatile surrogates consistent with uncertainties in their predicted boiling points, confirms that these can significantly affect the calculated SOA concentrations (by a factor of two in the example shown).

Semi-volatile compounds were assigned to surrogates in the UCD-CACM model according to structure, source, volatility, and ability to dissociate (for those compounds soluble in water) (Griffin et al., 2005). The driving force for gas/aerosol partitioning of each organic compound is the product $f_{i} p_{i}^{o}$, whereas liquid/liquid partitioning within the aerosol is influenced only by $f_{i}$ (in addition to the quantities of material present in both phases which determines mole fraction). The comparisons presented in Sect. 3.2 of Paper 2 show that the estimated vapour pressures of the 38 compounds assigned to the 10 semi-volatile surrogates vary widely, and are not always consistent with the value calculated for the surrogate itself, even using only a single estimation method. This difficulty seems likely to occur for any model, given the sensitivity of vapour pressure to molecular structure and the functional groups present (illustrated in Table 1 of Paper 2 for some $\mathrm{C}_{4}$ compounds). One way to address this problem would be to separate the choice of surrogate compounds, and assignment of physical properties for estimating $p^{o}$ and for the calculation of activity coefficients, and to base the properties of the surrogates more closely on those of the compounds they represent.

For example, values of $p^{o}$ and $\Delta \mathrm{H}_{\text {vap }}^{o}$ for the surrogates could be based upon averages of measured or predicted vapour pressures for the individual compounds assigned to them. They could be grouped, for surrogates used in gas/aerosol partitioning calculations, according to their vapour pressures (rather than by structure). If the calculated vapour pressures listed in Table 8 of Paper 2 are divided into 10 ranges - one for each surrogate - then each would include compounds with vapour pressures ranging over a factor of about 5.7 (an increment of $0.65 \log _{10}$ units). This appears reasonable given that the uncertainties in the estimated vapour pressures of the compounds, and their current surrogates in the UCD-CACM model, are greater than this.

In an analogous way, the assignment of individual compounds to surrogates in the aqueous phase could be based upon similarities of the UNIFAC-calculated activity coefficients for systems of representative composition. In this case, because of the formulation of UNIFAC, groupings more directly based upon molecular structure are likely. In the UCDCACM model the existing assignment of surrogates quite successfully duplicates the liquid/liquid phase partitioning calculated for the individual constituent compounds. We have not, however, compared absolute values of the activity coefficients for that calculation. They might still vary considerably within the groups assigned to each surrogate.

There are likely to be difficulties with using more than one assignment of surrogate compounds, as this implies changes to the sets of variables used in the phase partitioning calculation and in the activity coefficients used in the gas/aerosol, and liquid/liquid, elements of the calculation. The approach could not be used in AIM, for example, but might be possible in the UCD-CACM model because the gas/aerosol partitioning and internal aerosol equilibrium calculations are separate. For AIM and similar models it may be necessary to assign individual compounds to a single set of surrogates, but chosen for similarities in both $p^{o}$ and activity coefficients. In this case the significant quantity would be $f \times p^{o}$, and the value of $f$ would be the value for the component dissolved in either water (for those occurring mainly in the aqueous phase), or compound P8 (for those occurring mainly in the hydrophobic phase). 
The dissociation of organic acids (here surrogates A1, A2, A4, B1 and B2) in the aerosol aqueous phase can potentially affect both the total amounts of the compounds present in the aerosol phase, and also aerosol $\mathrm{pH}$. The magnitude of this influence depends upon (i) the dissociation constants of the organic surrogate compounds; (ii) the activity coefficients calculated for, or assigned to, the undissociated organic acid molecule and organic acid anions, and (iii) the degree to which $\mathrm{pH}$ is controlled by the inorganic electrolytes present. For fogs and cloud water, where solute concentrations are low, an expression for the activity coefficients of the organic acid anions that includes the Debye-Hückel limiting law is desirable. For example, in AIM the activity coefficients of the organic acid anions are determined by analogy with $\mathrm{SO}_{4(\mathrm{aq})}^{2-}$ and $\mathrm{HSO}_{4(\mathrm{aq})}^{-}$. In the absence of further information this seems reasonable especially as the dissociation constants of the surrogate compounds (except for simple dicarboxylic acids), and the compounds they represent, are not well established.

In the simulations presented in this study RH does not exceed $80 \%$ and most aerosol acidity comes from inorganic components of the aerosol. Although the degrees of dissociation of $\mathrm{B} 2$, and particularly A1, calculated by the UCDCACM and AIM models are very different, the effect on the calculated aerosol burden of SOA is minor as they are present in only small amounts compared to A2. The treatment of dissociation will be most important in two situations: where organic acids are the main sources of acidity in the aerosol, and in neutral to alkaline cases where dissociation will be greatest. An explicit treatment of bisulphate dissociation is also necessary. However, compared to the effects of uncertainties in vapour pressures of the SOA forming compounds, and the approximations inherent in using lumped surrogates for partitioning calculations, the impact of errors and approximations in the treatment of organic acid dissociation on SOA yield appears to be small.

This study has identified three elements of the gas/aerosol partitioning calculation where simplifications in the UCDCACM model, and therefore gains in efficiency, are possible. First, the calculation of organic acid dissociation can be neglected. Second, it is not necessary to calculate the liquid/liquid partitioning of those organic compounds which exist almost entirely in a single liquid phase. Third, the activity coefficients of the organic compound in the aerosol liquid phases are determined, in both UCD-CACM and AIM models, by interactions with the dominant solvents which are water and P8. It seems likely that in many simulations the values of the activity coefficients will therefore vary little, and in such cases could be determined just once at the beginning of the simulation rather than multiple times during every gas/aerosol and liquid/liquid partitioning calculation.

\subsection{Inorganic components}

As noted above, the influence of the inorganic electrolyte content of the aerosol partitioning of the semi-volatile SOA compounds is exerted mainly via aerosol water content: the relationship between water activity (RH) and concentration at moderate to high $\mathrm{RH}$, and the formation of solids at low $\mathrm{RH}$ leading to the eventual efflorescence (drying out) of the aerosol.

There are significant differences between most of the inorganic thermodynamic modules in current use, and we have compared the differences between the UCD-CACM model and AIM in some detail. The UCD-CACM model has dynamically controlled partitioning between the gas phase and 15 aerosol size bins (of which only the largest 10 have been considered here), and with lower limits to the amount of aerosol water set for each bin. In contrast, AIM is a bulk equilibrium thermodynamic model with a more complex treatment of aqueous mixtures, no lower limit to the aerosol water amount, and a larger set of possible solids. However, it is clear from the comparisons shown in Sect. 3.1.1 that the effects of these differences on the calculated amounts of aerosol, and the partitioning of both organic compounds and the key volatile inorganic compounds $\mathrm{NH}_{3}$ and $\mathrm{HNO}_{3}$, is often small.

The effects of the differences between the models are greatest under conditions where the aerosol is predicted by AIM to contain little or no liquid water. This occurs in the afternoon of the diurnal cycle (when the RH is lowest) and virtually all the water soluble SOA material is returned to the gas phase in the AIM simulation. In the UCD-CACM model the aerosol water does not fall below an assigned lower limit (see Figs. 7 and 11), resulting in the retention of the water soluble organic compounds. This retention is also seen in the atmosphere - probably for other reasons - and the use of a lower limit to aerosol water is an artificial constraint within the model. It would be preferable to directly model either metastable aqueous aerosols, which are supersaturated with respect to the solids that might form, or the equilibrium state of the aerosol which is allowed to dry out completely at low $\mathrm{RH}$.

The differences between the inorganic models, in terms of $\mathrm{HNO}_{3}$ and $\mathrm{NH}_{3}$ partitioning, are less in the simulated diurnal cycle than might be expected from the analysis in Sect. 3.1.1. This is because the aerosol is largely acidic until the early afternoon, and $\mathrm{pNH}_{3}$ negligibly low, but an injection of $\mathrm{NH}_{3}$ as the parcel passes over a region of intensive farming results in the air parcel being dominated by this species, which is mostly in the gas phase. Consequently, in the latter part of the day even large changes in the total ammonia present in the aerosol have only a small influence on the amount in the gas phase. Under atmospheric conditions where the partitioning of both $\mathrm{HNO}_{3}$ and $\mathrm{NH}_{3}$ is more evenly balanced between both phases, differences between the inorganic thermodynamic models would be more apparent. It is worth noting 


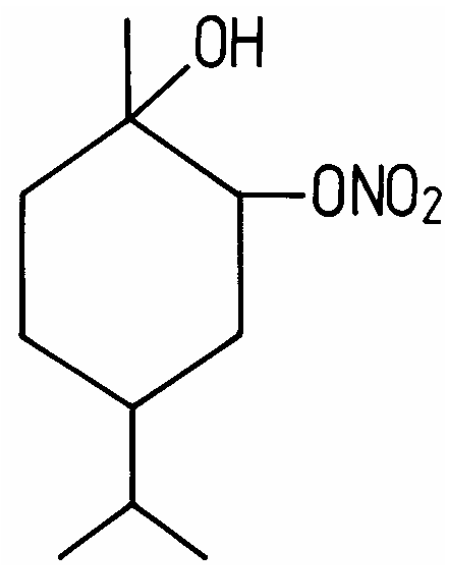

Fig. 22. The revised structure of surrogate compound B5.

that neither AIM nor other current models include the influences of dissolved ions on the activity coefficient of aqueous $\mathrm{NH}_{3}$, which directly affects the calculated partial pressure. This is in spite of the fact that data for at least some of the main aerosol components, including $\left(\mathrm{NH}_{4}\right)_{2} \mathrm{SO}_{4}$ and $\mathrm{NaCl}$, have been available for some time (Clegg and Brimblecombe, 1989). For example, the value of $\gamma \mathrm{NH}_{3}$ in aqueous $\left(\mathrm{NH}_{4}\right)_{2} \mathrm{SO}_{4}$ ranges from 1.16 at $98 \% \mathrm{RH}$, to 1.96 at $90 \%$ and 2.68 at $80 \% \mathrm{RH}$. The fact that these activity coefficients are greater than unity means that the amounts of $\mathrm{NH}_{3}$ in the gas phase will be underpredicted for aerosols that are neutral or alkaline by models that assume $\gamma \mathrm{NH}_{3}=1$.

\subsection{Future developments}

The physical properties of polar multifunctional organic compounds, such as those that make up SOA, are among the most difficult to predict. This is reflected in the results in Paper 2, where the wide variations in estimated $p^{o}$ add a significant uncertainty to the calculated gas/aerosol partitioning at moderate to low RH. While models based upon an explicit chemistry must remain consistent with the known properties of the compounds, these uncertainties are large enough - and unlikely to decrease much in the near future - that field data and the results of laboratory studies of SOA formation are still needed to optimize the models. To some extent this is already done: the treatment of SOA formation in CMAQ is based directly upon chamber studies of SOA formation (Yu et al., 2007) and in the UCD-CACM model the vapour pressures of the ten SOA surrogates have been adjusted to be consistent with chamber measurements of aerosol formation from aromatic and monoterpene oxidation (Griffin et al., 2005).

It also seems likely that further advances in explicit models will come more from laboratory and field measurements than from improved predictive techniques for either vapour pressures, or from activity coefficient models that better integrate

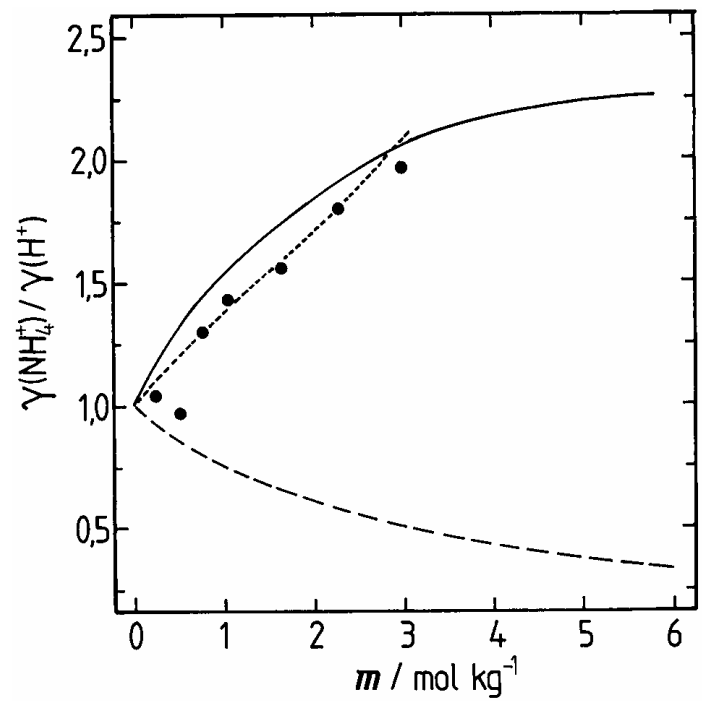

Fig. 23. The reciprocal $\gamma \mathrm{NH}_{4}^{+} / \gamma \mathrm{H}^{+}$in pure aqueous $\left(\mathrm{NH}_{4}\right)_{2} \mathrm{SO}_{4}$ of molality $\boldsymbol{m}$ at $298.15 \mathrm{~K}$. Dots - derived from the measurements of Maeda and Iwata (1997); dotted line - calculated using the molality based model of Pitzer (1992); solid line - AIM; dashed line method of Kusik and Meissner (1978) as used in the UCD-CACM model.

the treatments of inorganic and uncharged organic components of the aerosol. While dissolved salts undoubtedly influence the activities of dissolved organic compounds (and vice versa), uncertainties in the vapour pressures of the organic compounds appear to be large compared to the probable effects on activity coefficients. Except where salt-organic interactions induce a qualitative change in behaviour, promoting a chemical reaction or inducing a phase separation for example, the current relatively simple treatment of the thermodynamics of the aqueous aerosol phase for inorganic/organic mixtures seems justified. We note that the observed lowering of the deliquescence RH of mixtures of inorganic and organic solutes is reasonably approximated by the influence of both solutes on the water activity of the mixture (see references in Clegg and Seinfeld, 2006a, b), and that this effect is reproduced by both the ZSR relationship (used in the UCD-CACM and other models) and in AIM using the approach described by Clegg et al. (2001).

Future studies with the UCD-CACM model will include revisions to the assignments of compounds to surrogate species and the vapour pressures of the surrogates. Clearly an explicit representation of oligomer formation is also desirable as data describing the parent compounds and rate limiting steps in the formation process become available. 
Table 3. UNIFAC Groups and Examples of Their Use.

\begin{tabular}{lll}
\hline Group No. & Name & Example \\
\hline 11 & $\mathrm{CH} 3$ & ethane: $2 \mathrm{CH} 3$ \\
12 & $\mathrm{CH} 2$ & n-butane: $2 \mathrm{CH} 3,2 \mathrm{CH} 2$ \\
13 & $\mathrm{CH}$ & isobutane: $3 \mathrm{CH} 3,1 \mathrm{CH}$ \\
14 & $\mathrm{C}$ & neopentane: $4 \mathrm{CH} 3,1 \mathrm{C}$ \\
24 & $\mathrm{CH}=\mathrm{C}$ & 2-methyl-2-butene: $2 \mathrm{CH} 3,1 \mathrm{CH}=\mathrm{C}$ \\
25 & $\mathrm{C}=\mathrm{C}$ & 2,3-dimethylbutene: $4 \mathrm{CH} 3,1 \mathrm{C}=\mathrm{C}$ \\
31 & $\mathrm{ACH}$ & napthalene: $8 \mathrm{ACH}, 2 \mathrm{AC}$ \\
32 & $\mathrm{AC}$ & styrene: $1 \mathrm{CH} 2=\mathrm{CH}, 5 \mathrm{ACH}, 1 \mathrm{AC}$ \\
41 & $\mathrm{ACCH} 3$ & toluene: $5 \mathrm{ACH}, 1 \mathrm{ACCH} 3$ \\
42 & $\mathrm{ACCH} 2$ & ethylbenzene: $5 \mathrm{ACH}, 1 \mathrm{ACCH} 2,1 \mathrm{CH} 3$ \\
50 & $\mathrm{OH}$ & propanol-2: $2 \mathrm{CH} 3,1 \mathrm{CH}, 1 \mathrm{OH}$ \\
70 & $\mathrm{H} 2 \mathrm{O}$ & water: $1 \mathrm{H} 2 \mathrm{O}$ \\
80 & $\mathrm{ACOH}$ & phenol: $5 \mathrm{ACH}, 1 \mathrm{ACOH}$ \\
91 & $\mathrm{CH} 3 \mathrm{CO}$ & butanone: $1 \mathrm{CH} 3,1 \mathrm{CH} 2,1 \mathrm{CH} 3 \mathrm{CO}$ \\
92 & $\mathrm{CH} 2 \mathrm{CO}$ & pentanone-3: $2 \mathrm{CH} 3,1 \mathrm{CH} 2,1 \mathrm{CH} 2 \mathrm{CO}$ \\
100 & $\mathrm{CHO}$ & propionaldehyde: $1 \mathrm{CH} 3,1 \mathrm{CH} 2,1 \mathrm{CHO}$ \\
201 & $\mathrm{COOH}$ & acetic acid: $1 \mathrm{CH} 3,1 \mathrm{COOH}$ \\
262 & $\mathrm{CH} 2 \mathrm{NO} 2$ & propane-1-nitro: $1 \mathrm{CH} 3,1 \mathrm{CH} 2,1 \mathrm{CH} 2 \mathrm{NO} 2$ \\
270 & $\mathrm{ACN} 2$ & benzene-nitro: $5 \mathrm{ACH}, 1 \mathrm{ACNO} 2$ \\
\hline
\end{tabular}

Table 4. UNIFAC Group Definitions of Surrogate Compounds.

\begin{tabular}{|c|c|c|c|c|c|c|c|c|c|c|c|c|}
\hline Compound & Group & \# & Group & \# & Group & $\#$ & Group & $\#$ & Group & $\#$ & Group & \# \\
\hline water & 70 & 1 & & & & & & & & & & \\
\hline $\mathrm{P} 1$ & 11 & 2 & 12 & 27 & & & & & & & & \\
\hline $\mathrm{P} 2$ & 12 & 2 & 201 & 2 & & & & & & & & \\
\hline P3 & 32 & 4 & 31 & 6 & 201 & 2 & & & & & & \\
\hline P4 & 32 & 10 & 31 & 12 & & & & & & & & \\
\hline P5 & 11 & 8 & 12 & 11 & 13 & 6 & 14 & 5 & & & & \\
\hline P6 & 31 & 4 & 32 & 2 & 201 & 2 & & & & & & \\
\hline P7 & 11 & 1 & 12 & 16 & 201 & 1 & & & & & & \\
\hline P8 & 11 & 12 & 12 & 6 & 13 & 6 & 14 & 4 & & & & \\
\hline B1 (S6) & 31 & 1 & 32 & 1 & 80 & 1 & 201 & 1 & 41 & 2 & 270 & 1 \\
\hline B2 (S7) & 201 & 1 & 100 & 1 & 32 & 2 & 31 & 2 & 41 & 2 & & \\
\hline B3 (S8) & 31 & 6 & 32 & 2 & 41 & 1 & 42 & 1 & 262 & 1 & & \\
\hline B4 (S9) & 50 & 1 & 11 & 2 & 12 & 12 & 13 & 2 & 262 & 1 & & \\
\hline B5 (S10) & 11 & 3 & 12 & 3 & 13 & 3 & 50 & 1 & 14 & 1 & 262 & 1 \\
\hline $\mathrm{A} 1$ (S1) & 201 & 2 & & & & & & & & & & \\
\hline A2 (S2) & 201 & 2 & 100 & 1 & 24 & 2 & 11 & 1 & & & & \\
\hline A3 (S3) & 11 & 2 & 100 & 2 & 50 & 1 & 24 & 1 & 25 & 1 & & \\
\hline A4 (S4) & 50 & 1 & 201 & 1 & 91 & 1 & 11 & 2 & 13 & 2 & 24 & 1 \\
\hline A5 (S5) & 91 & 1 & 12 & 2 & 13 & 3 & 11 & 2 & 50 & 1 & 100 & 1 \\
\hline
\end{tabular}

Notes: the structures are as given by Griffin et al. (2003), with the exception of the correction shown in Fig. 22 for B5. The substitution of $-\mathrm{CH}_{2}-\mathrm{NO}_{2}$ for $-\mathrm{O}-\mathrm{NO}_{2}$ is noted in the text. Column "\#” gives the number of occurrences of the group in each molecule. 
Table 5. The UCD-CACM and Extended AIM Models.

\begin{tabular}{|c|c|c|}
\hline feature & UCD-CACM & Extended $A I M$ \\
\hline $\begin{array}{l}\text { calculation of inorganic ac- } \\
\text { tivities }\end{array}$ & Kusik and Meissner (1978) & $\begin{array}{l}\text { Pitzer-Simonson-Clegg (Clegg et al., } \\
\text { 1992) }\end{array}$ \\
\hline organic activities & UNIFAC & $\begin{array}{l}\text { UNIFAC (for this study), other models } \\
\text { can also be used }\end{array}$ \\
\hline gas/aerosol partitioning & dynamic & equilibrium \\
\hline size distribution & 10 size bins & bulk (single bin) \\
\hline inorganic composition & $\mathrm{H}^{+}, \mathrm{NH}_{4}^{+}, \mathrm{Na}^{+}, \mathrm{Cl}^{-}, \mathrm{NO}_{3}^{-}, \mathrm{SO}_{4}^{2-}$ & $\begin{array}{l}\mathrm{H}^{+}, \mathrm{NH}_{4}^{+},\left(\mathrm{Na}^{+}, \mathrm{Cl}^{-}\right), \mathrm{Br}^{-}, \mathrm{NO}_{3}^{-} \text {, } \\
\mathrm{SO}_{4}^{2-} \text { (in different combinations, see } \\
\text { Wexler and Clegg, 2002) }\end{array}$ \\
\hline $\mathrm{HSO}_{4}^{-}$dissociation & not included & treated explicitly \\
\hline liquid phases & aqueous, hydrophobic & aqueous, hydrophobic \\
\hline gases & $\begin{array}{l}\mathrm{HNO}_{3}, \mathrm{NH}_{3}, \mathrm{HCl} \text { and semi-volatile or- } \\
\text { ganic compounds }\end{array}$ & $\begin{array}{l}\mathrm{HNO}_{3}, \mathrm{NH}_{3}, \mathrm{HCl}, \mathrm{H}_{2} \mathrm{SO}_{4} \text {, and semi- } \\
\text { volatile organic compounds }\end{array}$ \\
\hline solids & $\begin{array}{l}\mathrm{NaCl}, \mathrm{NaNO}_{3}, \mathrm{Na}_{2} \mathrm{SO}_{4}, \mathrm{NH}_{4} \mathrm{Cl}, \\
\mathrm{NH}_{4} \mathrm{NO}_{3},\left(\mathrm{NH}_{4}\right)_{2} \mathrm{SO}_{4},\left(\mathrm{NH}_{4}\right)_{2} \mathrm{H}\left(\mathrm{SO}_{4}\right)_{2}, \\
\mathrm{NH}_{4} \mathrm{HSO}_{4}, \mathrm{NaHSO}_{4}\end{array}$ & $\begin{array}{l}\mathrm{NaCl}, \mathrm{NaNO}_{3}, \mathrm{Na}_{2} \mathrm{SO}_{4}, \mathrm{NH}_{4} \mathrm{Cl}, \\
\mathrm{NH}_{4} \mathrm{NO}_{3},\left(\mathrm{NH}_{4}\right)_{2} \mathrm{SO}_{4},\left(\mathrm{NH}_{4}\right)_{2} \mathrm{H}\left(\mathrm{SO}_{4}\right)_{2}, \\
\mathrm{NH}_{4} \mathrm{HSO}_{4}, \mathrm{NaHSO}_{4}, 2 \mathrm{NH}_{4} \mathrm{NO}_{3} \cdot \\
\left(\mathrm{NH}_{4}\right)_{2} \mathrm{SO}_{4}, 3 \mathrm{NH}_{4} \mathrm{NO}_{3} \cdot\left(\mathrm{NH}_{4}\right)_{2} \mathrm{SO}_{4}, \\
\mathrm{NH}_{4} \mathrm{HSO}_{4} \cdot \mathrm{NH}_{4} \mathrm{NO}_{3}, \mathrm{Na}_{2} \mathrm{SO}_{4} \cdot \\
10 \mathrm{H}_{2} \mathrm{O}, \mathrm{Na}_{3} \mathrm{H}\left(\mathrm{SO}_{4}\right)_{2}, \mathrm{NaHSO}_{4} \cdot \mathrm{H}_{2} \mathrm{O}, \\
\mathrm{NaH}_{3}\left(\mathrm{SO}_{4}\right)_{2} \cdot \mathrm{H}_{2} \mathrm{O},\left(\mathrm{NH}_{4}\right)_{2} \mathrm{SO}_{4} \cdot \\
\mathrm{Na}_{2} \mathrm{SO}_{4} \cdot 4 \mathrm{H}_{2} \mathrm{O}, \mathrm{Na}_{2} \mathrm{SO}_{4} \cdot \mathrm{NaNO}_{3} \cdot \mathrm{H}_{2} \mathrm{O}, \\
2 \mathrm{NaNO}_{3} \cdot \mathrm{NH}_{4} \mathrm{NO}_{3}+\text { low temperature } \\
\mathrm{HNO}_{3}, \mathrm{H}_{2} \mathrm{SO}_{4} \text { and } \mathrm{HCl} \text { hydrates }\end{array}$ \\
\hline minimum aerosol water & $\begin{array}{l}\text { yes (to prevent the ionic strength going } \\
\text { outside the range of the activity coeffi- } \\
\text { cient model) }\end{array}$ & $\begin{array}{l}\text { no, and can also calculate the properties } \\
\text { of metastable aerosols that do not dry out } \\
\text { at low relative humidity. }\end{array}$ \\
\hline
\end{tabular}

\section{Appendix A}

\section{The surrogate compounds}

The molecular structures of the eighteen surrogate compounds in the UCD-CACM model are as given by Griffin et al. (2003), except that compound B5 (S10 in Fig. 1 of Griffin et al., 2003) has been corrected as described by Griffin et al. (2005). The hopane, compound P5, differs from the structure for CAS Registry number 471-62-5 only in the position of one $-\mathrm{CH}_{3}$ group and the latter is assumed here. The structure of B5 is shown in Fig. 22. Formulae, CAS Registry numbers and molar masses are as follows: $\mathrm{C}_{2} \mathrm{H}_{2} \mathrm{O}_{4}$, 144-62-7, 90.3 g (A1); $\mathrm{C}_{8} \mathrm{H}_{8} \mathrm{O}_{5}, 538367-55-4,184.2 \mathrm{~g}$ (A2); $\mathrm{C}_{8} \mathrm{H}_{10} \mathrm{O}_{3}, 538367-56-5,154.2 \mathrm{~g}(\mathrm{~A} 3) ; \mathrm{C}_{9} \mathrm{H}_{14} \mathrm{O}_{4}, 538367-$ 57-6, 186.2 g (A4); $\mathrm{C}_{10} \mathrm{H}_{18} \mathrm{O}_{3}, 538367-58-7,186.3 \mathrm{~g}$ (A5); $\mathrm{C}_{9} \mathrm{H}_{9} \mathrm{NO}_{5}, 538367-59-8,211.2 \mathrm{~g}(\mathrm{~B} 1) ; \mathrm{C}_{10} \mathrm{H}_{10} \mathrm{O}_{3}, 538367-$ 60-1, 178.2 g (B2); $\mathrm{C}_{12} \mathrm{H}_{11} \mathrm{NO}_{3}, 538367-61-2,217.2 \mathrm{~g}$ (B3); $\mathrm{C}_{16} \mathrm{H}_{33} \mathrm{NO}_{4}, 538367-62-3,303.4 \mathrm{~g}$ (B4); $\mathrm{C}_{10} \mathrm{H}_{19} \mathrm{NO}_{4}$,
$217.3 \mathrm{~g}$ (B5, corrected); $\mathrm{C}_{29} \mathrm{H}_{60}, 630-03-5,408.8 \mathrm{~g}$ (P1); $\mathrm{C}_{4} \mathrm{H}_{6} \mathrm{O}_{4}, 110-15-6,118.1 \mathrm{~g}(\mathrm{P} 2) ; \mathrm{C}_{12} \mathrm{H}_{8} \mathrm{O}_{4}, 1141-38-4$, 216.2 g (P3); $\mathrm{C}_{22} \mathrm{H}_{12}, 191-24-2,276.3 \mathrm{~g}(\mathrm{P} 4) ; \mathrm{C}_{30} \mathrm{H}_{52}$, 471-62-5, 412.7 g (P5); $\mathrm{C}_{8} \mathrm{H}_{6} \mathrm{O}_{4}, 88-99-3,166.1 \mathrm{~g}$ (P6); $\mathrm{C}_{18} \mathrm{H}_{36} \mathrm{O}_{2}, 57-11-4,284.5 \mathrm{~g}(\mathrm{P} 7) ; \mathrm{C}_{28} \mathrm{H}_{54}, 538367-70-3$, $390.7 \mathrm{~g}(\mathrm{P} 8)$.

\section{Dissociation constants}

Dissociation of the semi-volatile organic surrogates containing $-\mathrm{COOH}$ groups(s) is calculated using dissociation constants $K_{d 1}$ and $K_{d 2}$ defined in Eqs. (3a) and (3b). The following values are given in units of $\mathrm{mol} \mathrm{kg}^{-1}$, and the equilibrium constants are assumed not to vary with temperature: $1.70 \times 10^{-3}$ ( $K_{d 1}$ for B1), $7.33 \times 10^{-5}\left(K_{d 1}\right.$ for B2), $5.4 \times 10^{-2}\left(K_{d 1}\right.$ for A1), $5.2 \times 10^{-5}\left(K_{d 2}\right.$ for A1), $3.7 \times 10^{-5}$ ( $K_{d 1}$ for A2), $3.9 \times 10^{-6}\left(K_{d 2}\right.$ for A2), $6.52 \times 10^{-4}\left(K_{d 1}\right.$ for $\mathrm{A} 4)$. 


\section{UNIFAC group definitions of the surrogate compounds}

For UNIFAC calculations of the activity coefficients in liquid mixtures the organic components are defined in terms of the structural groups of which they are composed (and without regard to position). The UNIFAC groups that occur in compounds P1-8, A1-5 and B1-5 are listed in Table 3. There is no UNIFAC $-\mathrm{O}-\mathrm{NO}_{2}$ group such as occurs in compounds $\mathrm{B} 3-5$. We have therefore assumed the composition $-\mathrm{CH}_{2}-\mathrm{NO}_{2}$ for activity coefficient calculations. The UNIFAC definitions of all of the surrogate species are given in Table 4. Parameters for interactions between seven pairs of the following main UNFAC groups are unknown and therefore not included in the model: $\mathrm{C}=\mathrm{C}, \mathrm{CNO}_{2}, \mathrm{ACNO}_{2}, \mathrm{CHO}$ and $\mathrm{ACOH}$. We note also the existence of an alternative "Dortmund" UNIFAC parameter set which is optimised for liquid/liquid equilibrium, rather than vapour/liquid equilibrium calculations (e.g., Jakob et al., 2006). We have not tested the use of this parameter set in our simulations.

\section{Estimation of vapour pressures of the surrogate com- pounds}

The vapour pressures of the surrogate compounds estimated using the Myrdal and Yalkowsky (1997) equation, and listed in Tables 5-7 of Paper 2, require boiling points at atmospheric pressure, a structural parameter $\tau$, and a hydrogen bonding number HBN. In earlier versions of the UCDCACM model there were some errors in these parameters. The correct values are listed in Table 9 of Paper 2.

\section{Appendix B}

The main features of the UCD-CACM and extended AIM thermodynamic models are listed in Table 5. AIM treats many more solids, but the only ones not included in the UCD-CACM model and relevant to this study are the double salts $2 \mathrm{NH}_{4} \mathrm{NO}_{3} \cdot\left(\mathrm{NH}_{4}\right)_{2} \mathrm{SO}_{4(\mathrm{~s})}$ and $3 \mathrm{NH}_{4} \mathrm{NO}_{3} \cdot\left(\mathrm{NH}_{4}\right)_{2} \mathrm{SO}_{4(\mathrm{~s})}$. Some of the largest differences between the UCD-CACM and extended AIM inorganic thermodynamic treatments occur in the calculated equilibrium partial pressures of the inorganic gases $\mathrm{HNO}_{3}$ and $\mathrm{NH}_{3}$ shown in Fig. 10, and are analysed here. The gas/liquid equilibrium of $\mathrm{HNO}_{3}$ and $\mathrm{NH}_{3}$ are described, on the molality scale, by:

$$
\begin{aligned}
& K_{H}\left(\mathrm{HNO}_{3}\right)=a \mathrm{H}^{+} a \mathrm{NO}_{3}^{-} / \mathrm{pHNO}_{3} \\
& =m \mathrm{H}^{+} m \mathrm{NO}_{3}^{-} \gamma \mathrm{H}^{+} \gamma \mathrm{NO}_{3}^{-} / \mathrm{pHNO}_{3} \\
& =m \mathrm{H}^{+} m \mathrm{NO}_{3}^{-} \gamma \mathrm{HNO}_{3}^{2} / \mathrm{pHNO}_{3} \\
& K_{H}^{\prime}\left(\mathrm{NH}_{3}\right)=a \mathrm{NH}_{4}^{+} /\left(a \mathrm{H}^{+} \mathrm{pNH}_{3}\right) \\
& =m \mathrm{NH}_{4}^{+}\left(\gamma \mathrm{NH}_{4}^{+} / \gamma \mathrm{H}^{+}\right) /\left(m \mathrm{H}^{+} \mathrm{pNH}_{3}\right)
\end{aligned}
$$

where prefix $a$ denotes activity, $m$ molality, and $\gamma_{i}$ is the activity coefficient of ion $i$. Symbol $K_{H}\left(\mathrm{HNO}_{3}\right)$ is the molality based Henry's law constant of $\mathrm{HNO}_{3}$ $\left(2.63 \times 10^{-6} \mathrm{~mol}^{2} \mathrm{~kg}^{-2} \mathrm{~atm}^{-1}\right.$ at $298.15 \mathrm{~K}$, Carslaw et al., $1995)$, and $K_{H}^{\prime}\left(\mathrm{NH}_{3}\right)\left(1.066 \times 10^{-11} \mathrm{~atm}^{-1}\right.$ at $\left.298.15 \mathrm{~K}\right)$ is an equilibrium constant equivalent to the Henry's law constant of $\mathrm{NH}_{3}$ divided by the acid dissociation constant of $\mathrm{NH}_{4(\mathrm{aq})}^{+}$. The mean activity coefficient of $\mathrm{HNO}_{3}, \gamma \mathrm{HNO}_{3}$, is equal to the square root of the product $\left(\gamma \mathrm{H}^{+} \gamma \mathrm{NO}_{3}^{-}\right)$. Note that in the acidic solutions in this example the dissociation of $\mathrm{NH}_{4(\mathrm{aq})}^{+}$to $\mathrm{NH}_{3(\mathrm{aq})}$ is small and can be neglected.

It is clear from the above equations that the differences between the predictions of the two models will be mainly caused by differences in $a \mathrm{H}^{+}$: a lower value predicted by AIM results in both a smaller equilibrium $\mathrm{pHNO}_{3}$ and a higher $\mathrm{pNH}_{3}$ according to the equations above. Figure 9 of Wexler and Seinfeld (1991) shows that stoichiometric activity coefficients of aqueous $\mathrm{H}_{2} \mathrm{SO}_{4}$ are not well reproduced by that model. However, the main reason for the differences in predicted vapour pressures is likely to be the fact that the $\mathrm{HSO}_{4(\mathrm{aq})}^{-} \leftrightarrow \mathrm{H}_{(\mathrm{aq})}^{+}+\mathrm{SO}_{4(\mathrm{aq})}^{2-}$ equilibrium is not recognized in the Kusik and Meissner equations used to predict inorganic activities in the UCD-CACM model. This is verified, below, by comparing both models to laboratory data.

Maeda and Iwata (1997) have measured the acid dissociation constant of $\mathrm{NH}_{4(\mathrm{aq})}^{+}$in aqueous $\left(\mathrm{NH}_{4}\right)_{2} \mathrm{SO}_{4}$, on a total hydrogen ion basis, at $25^{\circ} \mathrm{C}$. These measurements can be used as a test of the models' ability to represent activities of $\mathrm{H}_{(\mathrm{aq})}^{+}$in solutions containing mainly $\left(\mathrm{NH}_{4}\right)_{2} \mathrm{SO}_{4}$ such as the aerosols in the larger size bins in Fig. 10. The experimental molal dissociation constants in Table 1 of Maeda and Iwata, $K_{a, m}$, are equivalent to:

$K_{a, m}=\left(m \mathrm{H}^{+}+m \mathrm{HSO}_{4}^{-}\right) m \mathrm{NH}_{3} / m \mathrm{NH}_{4}^{+}$

Introducing the thermodynamic dissociation constant of $\mathrm{HSO}_{4(\mathrm{aq})}^{-}, K_{a}^{o}\left(\mathrm{HSO}_{4}\right)$, Eq. (6) can be rewritten:

$$
\begin{aligned}
K_{a, m} & =\left(m \mathrm{H}^{+} m \mathrm{NH}_{3} / m \mathrm{NH}_{4}^{+}\right) \\
& {\left[1+\left(m / K_{a}^{o}\left(\mathrm{HSO}_{4}\right)\right)\left(\gamma \mathrm{H}^{+} \gamma \mathrm{SO}_{4}^{2-}\right) / \gamma \mathrm{HSO}_{4}^{-}\right] }
\end{aligned}
$$

where $m$ is the molality of $\left(\mathrm{NH}_{4}\right)_{2} \mathrm{SO}_{4}$ and $K_{a}^{o}\left(\mathrm{HSO}_{4}\right)$ has a value of $0.0105 \mathrm{~mol} \mathrm{~kg}^{-1}$ at $25^{\circ} \mathrm{C}$ (Clegg et al., 1994). The stoichiometric dissociation constant on a free $\mathrm{H}^{+}$ion basis (the first term in parentheses in Eq. 4) is equivalent to $K_{a, m}^{o} \times \gamma \mathrm{NH}_{4}^{+} /\left(\gamma \mathrm{H}^{+} \gamma \mathrm{NH}_{3}\right)$ where $K_{a, m}^{o}$ is the thermodynamic value of the dissociation constant which is $5.6885 \times 10^{-10} \mathrm{~mol} \mathrm{~kg}^{-1}$ at $25^{\circ} \mathrm{C}$ (Bates and Pinching, 1949). Substituting into Eq. (4) we obtain an expression for the reciprocal $\gamma \mathrm{NH}_{4}^{+} / \gamma \mathrm{H}^{+}$in the solution in terms only of $m$ and the activity coefficients of the other species present:

$$
\begin{aligned}
& \left(\gamma \mathrm{NH}_{4}^{+} / \gamma \mathrm{H}^{+}\right)=\left(K_{a, m} / K_{a, m}^{o}\right) \gamma \mathrm{NH}_{3} / \\
& {\left[1+\left(m / K_{a}^{o}\left(\mathrm{HSO}_{4}\right)\right)\left(\gamma \mathrm{H}^{+} \gamma \mathrm{SO}_{4}^{2-}\right) / \gamma \mathrm{HSO}_{4}^{-}\right]}
\end{aligned}
$$

Maeda and Iwata (1997) have shown that their experimental $K_{a, m}$ can be satisfactorily reproduced using a molality-based 
Pitzer activity coefficient model (Pitzer, 1991) using interaction parameters determined by Clegg and co-workers (Clegg and Brimblecombe, 1989; Clegg and Whitfield, 1992) from extensive experimental data for activity coefficients, solubilities and osmotic coefficients. We have used this model, together with Eq. (5) to obtain values of $\left(\gamma \mathrm{NH}_{4}^{+} / \gamma \mathrm{H}^{+}\right)$from the $K_{a, m}$ tabulated by Maeda and Iwata. Given that the value of $\gamma \mathrm{NH}_{4}^{+}$is determined by interactions with $\mathrm{SO}_{4}^{2-}$ in aqueous $\left(\mathrm{NH}_{4}\right)_{2} \mathrm{SO}_{4}$, and therefore known from data for the pure aqueous salt, comparisons of the modelled and experimental $\left(\gamma \mathrm{NH}_{4}^{+} / \gamma \mathrm{H}^{+}\right)$are essentially a test of the models' ability to predict $\gamma \mathrm{H}^{+}$which is central to the differences between the predicted vapour pressures shown in Fig. 10 and discussed above. We note that it is not possible to predict $K_{a, m}$ directly with the UCD-CACM model because neither $\mathrm{HSO}_{4(\mathrm{aq})}^{-}$nor $\mathrm{NH}_{3(\mathrm{aq})}$ are included as individual species. This lack of $\mathrm{NH}_{3}$ makes the model most applicable to atmospheric systems in which the aerosols are acidic.

Values of $\left(\gamma \mathrm{NH}_{4}^{+} / \gamma \mathrm{H}^{+}\right)$in aqueous $\left(\mathrm{NH}_{4}\right)_{2} \mathrm{SO}_{4}$ were calculated directly using AIM, recalling that the value of the reciprocal is the same on both the molality and mole fraction scales. The quantity was obtained from the UCD-CACM model by making use of the following relationships:

$$
\begin{aligned}
& \gamma\left(\mathrm{NH}_{4}\right)_{2} \mathrm{SO}_{4}=\left[\left(\gamma \mathrm{NH}_{4}^{+}\right)^{2} \gamma \mathrm{SO}_{4}\right]^{1 / 3} \\
& \gamma \mathrm{H}_{2} \mathrm{SO}_{4}=\left[\left(\gamma \mathrm{H}^{+}\right)^{2} \gamma \mathrm{SO}_{4}^{2-}\right]^{1 / 3} \\
& \left(\gamma \mathrm{NH}_{4}^{+} / \gamma \mathrm{H}^{+}\right)=\left(\gamma\left(\mathrm{NH}_{4}\right)_{2} \mathrm{SO}_{4} / \gamma \mathrm{H}_{2} \mathrm{SO}_{4}\right)^{3 / 2}
\end{aligned}
$$

Values of the reciprocal calculated by all three models are compared with those derived from the experimental data in Fig. 23. The molality-based model closely agrees with the measurements, as shown by Maeda and Iwata (1997), and AIM agrees reasonably well, though with a small positive deviation. However, the Kusik and Meissner thermodynamic approach yields a decrease in $\left(\gamma \mathrm{NH}_{4}^{+} / \gamma \mathrm{H}^{+}\right)$- the opposite trend to that observed - and at $6 \mathrm{~mol} \mathrm{~kg}^{-1}(80 \% \mathrm{RH})$ the two models differ by a factor of about 6.9. The results in the figure are consistent with the differences in predicted equilibrium $p \mathrm{HNO}_{3}$ and $\mathrm{pNH}_{3}$ in Fig. 8: values of $\left(\gamma \mathrm{NH}_{4}^{+} / \gamma \mathrm{H}^{+}\right)$ that are too low lead to a pressure ratio for $\mathrm{NH}_{3}$ that is too high and a ratio for $\mathrm{HNO}_{3}$ that is too low.

Acknowledgements. This research was supported by U.S. Environmental Protection Agency grant RD-831082 and Cooperative Agreement CR-831194001, by the Natural Environment Research Council of the UK (as a part of the Tropospheric Organic Chemistry Experiment, TORCH), and by the European Commission as part of EUCAARI (European Integrated Project on Aerosol Cloud, Climate and Air Quality Interactions). The work has not been subject to the U.S. EPA's peer and policy review, and does not necessarily reflect the views of the Agency and no official endorsement should be inferred. The authors would like to thank the Atmospheric Sciences Modelling Division (ASMD) of U.S. EPA for hosting S. L. Clegg while carrying out this study, and P. Bhave and other ASMD members for helpful discussions.
Edited by: R. Cohen

\section{References}

Bates, R. G. and Pinching, G. D.: Acidic dissociation constant of ammonium ion at $0^{\circ}$ to $50^{\circ} \mathrm{C}$, and the base strength of ammonia, J. Res. Nat. Bur. Standards, 42, 419-430, 1949.

Bian, F. and Bowman, F. M.: A lumping model for compositionand temperature-dependent partitioning of secondary organic aerosols, Atmos. Environ., 39, 1263-1274, 2005.

Carslaw, K. S., Clegg, S. L., and Brimblecombe, P.: A thermodynamic model of the system $\mathrm{HCl}-\mathrm{HNO}_{3}-\mathrm{H}_{2} \mathrm{SO}_{4}-\mathrm{H}_{2} \mathrm{O}$, including solubilities of $\mathrm{HBr}$, from $<200 \mathrm{~K}$ to $328 \mathrm{~K}$, J. Phys. Chem., 99, 11 557-11 574, 1995.

Chen, J., Mao, H., Talbot, R. W., and Griffin, R. J.: Application of the CACM and MPMPO modules using the CMAQ model for the Eastern United States, J. Geophys. Res., 111, D23S25, doi:10.1029/2006JD007603, 2006.

Clegg, S. L.: Extension of the Aerosol Inorganics Model to include organic compounds with user-defined properties, Report to U.S. EPA, Research Triangle Park, North Carolina, Requisition Reference No. U2D604, QT-RT-03-000685, 2004.

Clegg, S. L. and Brimblecombe, P.: Solubility of ammonia in pure aqueous and multicomponent solutions, J. Phys. Chem., 93, 7237-7248, 1989.

Clegg, S. L. and Brimblecombe, P.: Application of a multicomponent thermodynamic model to activities and thermal properties of $0-40 \mathrm{~mol} \mathrm{~kg}^{-1}$ aqueous sulphuric acid from $<200 \mathrm{~K}$ to $328 \mathrm{~K}$, J. Chem. Eng. Data, 40, 43-64, 1995.

Clegg, S. L., Brimblecombe P., and Wexler, A. S.: A thermodynamic model of the system $\mathrm{H}^{+}-\mathrm{NH}_{4}^{+}-\mathrm{Na}^{+}-\mathrm{SO}_{4}^{2-}-\mathrm{NO}_{3}^{-}-\mathrm{Cl}^{-}$ $-\mathrm{H}_{2} \mathrm{O}$ at at $298.15 \mathrm{~K}$, J. Phys. Chem., A102, 2155-2171, $1998 \mathrm{a}$.

Clegg, S. L., Brimblecombe, P., and Wexler, A. S.: A thermodynamic model of the system $\mathrm{H}^{+}-\mathrm{NH}_{4}^{+}-\mathrm{SO}_{4}^{2-}-\mathrm{NO}_{3}^{-}-\mathrm{H}_{2} \mathrm{O}$ at tropospheric temperatures, J. Phys. Chem., A102, 2127-2154, $1998 b$.

Clegg, S. L., Kleeman, M. J., Griffin, R. J., and Seinfeld, J. H.: Effects of uncertainties in the thermodynamic properties of aerosol components in an air quality model - Part 2: Predictions of the vapour pressures of organic compounds, Atmos. Chem. Phys., 8, 1087-1103, 2008,

http://www.atmos-chem-phys.net/8/1087/2008/.

Clegg, S. L., Pitzer, K. S., and Brimblecombe, P.: Thermodynamics of multicomponent, miscible, ionic solutions. II. Mixtures including unsymmetrical electrolytes, J. Phys. Chem., 96, 94709479, 1992.

Clegg, S. L., Rard, J. A., and Pitzer, K. S.: Thermodynamic properties of $0-6 \mathrm{~mol} \mathrm{~kg}^{-1}$ aqueous sulphuric acid from 273.15 to 328.15 K, J. Chem. Soc., Faraday Trans., 90, 1875-1894, 1994.

Clegg, S. L. and Seinfeld, J. H.: Improvement of the ZdanovskiiStokes-Robinson model for mixtures containing solutes of different charge types, J. Phys. Chem. A, 108, 1008-1017, 2004.

Clegg, S. L. and Seinfeld, J. H.: Thermodynamic models of aqueous solutions containing inorganic electrolytes and dicarboxylic acids at $298.15 \mathrm{~K}$. I. The acids as non-dissociating components, J. Phys. Chem. A, 110, 5692-5717, 2006a.

Clegg, S. L. and Seinfeld, J. H.: Thermodynamic models of aqueous solutions containing inorganic electrolytes and dicarboxylic 
acids at $298.15 \mathrm{~K}$, II. Systems including dissociation equilibria, J. Phys. Chem. A, 110, 5718-5734, 2006b.

Clegg, S. L., Seinfeld, J. H., and Brimblecombe, P.: Thermodynamic modelling of aqueous aerosols containing electrolytes and dissolved organic compounds, J. Aerosol Sci., 32, 713-738, 2001.

Clegg, S. L. and Simonson, J. M.: A BET model of the thermodynamics of aqueous multicomponent solutions at extreme concentration, J. Chem. Thermodyn., 31, 1457-1472, 2001.

Clegg, S. L. and Whitfield, M.: Activity coefficients in natural waters, in: Activity Coefficients in Electrolyte Solutions, edited by: Pitzer, K. S., CRC Press, Boca Raton, 279-434, 1991.

Fraser, M. P., Cass, G. R., Simoneit, B. R. T. and Rasmussen, R. A.: Air quality model evaluation data for organics. $4 . \mathrm{C}_{2}-\mathrm{C}_{36}$ nonaromatic hydrocarbons, Environ. Sci. Technol., 31, 2356-2367, 1997.

Fraser, M. P., Cass, G. R., Simoneit, B. R. T., and Rasmussen, R. A.: Air quality model evaluation data for organics. 5. $\mathrm{C}_{6}-\mathrm{C}_{22}$ nonpolar and semipolar aromatic compounds, Environ. Sci. Technol., 32, 1760-1770, 1998.

Fredenslund, A., Jones, R. L., and Prausnitz, J. M.: Groupcontribution estimation of activity coefficients in non-ideal liquid mixtures, AIChE J., 21, 1086-1098, 1975.

Griffin, R. J., Cocker III, D. R., Flagan, R. C., and Seinfeld, J. H.: Organic aerosol formation from the oxidation of biogenic hydrocarbons, J. Geophys. Res., 104, 3555-3567, 1999.

Griffin, R. J., Dabdub, D., and Seinfeld, J. H.: Secondary organic aerosol - 1. Atmospheric chemical mechanism for production of molecular constituents, J. Geophys. Res., 107(D17), 4332, doi:10.1029/2001JD000541, 2002.

Griffin, R. J., Dabdub, D., and Seinfeld, J. H.: Development and initial evaluation of a dynamic species-resolved model for gas phase chemistry and size-resolved gas/particle partitioning associated with secondary organic aerosol formation, J. Geophys. Res., 110(D5), 05304, doi:10.1029/2004JD005219, 2005.

Griffin, R. J., Nguyen, K., Dabdub, D., and Seinfeld, J. H.: A coupled hydrophobic-hydrophilic model for predicting secondary organic aerosol formation, J. Atmos. Chem., 44, 171-190, 2003.

Hansen, H. K., Rasmussen, P., Fedenenslund, A., Schiller, M., and Gmehling, J.: Vapour-liquid equilibria by UNIFAC group contribution. 5. Revision and extension, Ind. Eng. Chem. Res., 30, 2352-2355, 1991.

Held, T., Ying, Q., Kaduwela, A., and Kleeman, M. J.: Modelling particulate matter in the San Joaquin Valley with a sourceoriented externally mixed three-dimensional photochemical grid model, Atmos. Environ., 22, 3689-3711, 2004.

Jacobson, M. Z.: Studying the effects of calcium and magnesium on size-distributed nitrate and ammonium with EQUISOLV II, Atmos. Environ., 33, 3635-3649, 1997.

Jakob, A., Grensemann, H., Lohmann, J., and Gmehling, J.: Further development of modified UNIFAC (Dortmund): Revision and extension. 5. Ind. Eng. Chem. Res. 45, 7924-7933, 2006.

Jang, M. S., Carroll, B., Chandramouli, B., and Kamens, R. M.: Particle growth by acid-catalyzed heterogeneous reactions of organic carbonyls on preexisting aerosols, Environ. Sci. Technol., 37, 3828-3837, 2003.

Jaoui, M., Kleindienst, T. E., Lewandowski, M., Offenburg, J. H., and Edney, E. O.: Identification and quantificiation of aerosol polar oxygenated compounds bearing carboxylic or hydroxyl groups. 2. Organic tracer compounds from monoterpenes, Environ. Sci. Technol., 39, 5661-5673, 2005.

Jenkin, M. E., Saunders, S. M., Wagner, V., and Pilling, M. J.: Protocol for the development of the Master Chemical Mechanism, MCM v3 (Part B): tropospheric degradation of aromatic volatile organic compounds, Atmos. Chem. Phys., 3, 181-193, 2003, http://www.atmos-chem-phys.net/3/181/2003/.

Kalberer, M., Sax, M., and Samburova, V.: Molecular size evolution of oligomers in organic aerosols collected in urban atmospheres and generated in a smog chamber, Environ. Sci. Technol., 40, 5917-5922, 2006.

Kanakidou, M., Seinfeld, J. H., Pandis, S. N., Barnes, I., Dentener, F. J., Facchini, M. C., Van Dingenen, R., Ervens, B., Nenes, A., Nielsen, C. J., Swietlicki, E., Putaud, J. P., Balkanski, Y., Fuzzi, S., Horth, J., Moortgat, G. K., Winterhalter, R., Myhre, C. E. L., Tsigaridis, K., Vignati, E., Stephanou, E. G., and Wilson, J.: Organic aerosol and global climate modelling: a review, Atmos. Chem. Phys., 5, 1053-1123, 2005,

http://www.atmos-chem-phys.net/5/1053/2005/.

Kleeman, M. J. and Cass, G. R.: Source contributions to the size and composition distribution of urban particulate air pollution, Atmos. Environ., 32, 2803-2816, 1998.

Kleeman, M. J. and Cass, G. R.: A 3D Eulerian source-oriented model for an externally mixed aerosol, Environ. Sci. Technol., 35, 4834-4848, 2001.

Kleeman, M. J., Eldering, A., and Cass, G. R.: Modeling the airborne particle complex as a source-oriented external mixture, J. Geophys. Res., 102, 21 355-21 372, 1997.

Kleeman, M. J., Hughes, L. S., Allen, J. O., and Cass, G. R.: Source contributions to the size and composition distribution of atmospheric particles: Southern California in September, 1996, Environ. Sci. Technol., 33, 4331-4341, 1999.

Kleeman, M. J., Ying, Q., Lu, J., Mysliwiec, M. J., Griffin, R. J., Chen, J., and Clegg, S. L.: Source apportionment of secondary organic aerosol during a severe photochemical smog episode, Atmos. Environ., 41, 576-591, 2007.

Kusik, C. L. and Meissner, H. P.: Electrolytic activity coefficients in inorganic processing, AIChE J. Symp. Ser., 173, 14-20, 1978.

Maeda, M. and Iwata, T.: Dissociation constants of the ammonium ion and activity coefficients of ammonia in aqueous ammonium sulphate solutions, J. Chem. Eng. Data, 42, 1216-1218, 1997.

Marcolli, C., Luo, B. P., and Peter, Th.: Mixing of the organic aerosol fractions: liquids as the thermodynamically stable phases, J. Phys. Chem. A, 108, 2216-2224, 2004.

Myrdal, P. B. and Yalkowsky, S. H.: Estimating pure component vapour pressures of complex organic molecules, Ind. Eng. Chem. Res., 36, 2494-2499, 1997.

Mysliwiec, M. J. and Kleeman, M. J.: Source apportionment of secondary particulate matter in a polluted atmosphere, Environ. Sci. Technol., 36, 5376-5384, 2002.

Nannoolal, Y.: Development and critical evaluation of group contribution methods for the estimation of critical properties, liquid vapour pressure and liquid viscosity of organic compounds, $\mathrm{Ph} . \mathrm{D}$ Thesis, University of Kwazulu-Natal, 2007.

Nenes, A., Pandis, S. N., and Pilinis, C.: ISORROPIA: a new thermodynamic equilibrium model for multiphase multicomponent inorganic aerosols, Aquatic Geochem., 4, 123-152, 1998.

Odum, J. R., Hoffmann, T. P. W., Bowman, F., Collins, D., Flagan, R. C., Seinfeld, J. H.: Gas/particle partitioning and secondary 
organic aerosol yields, Environ. Sci. Technol., 30, 2580-2585, 1996.

Pitzer, K. S.: Ion interaction approach: theory and data correlation, in: Activity Coefficients in Electrolyte Solutions, edited by: Pitzer, K. S., CRC Press, Boca Raton, 75-153, 1991.

Pruppacher, H. R. and Klett, J. D.: Microphysics of Clouds and Precipitation, D. Reidel, Dordrecht, 1978.

Pun, B. K., Griffin, R. J., Seigneur, C., and Seinfeld, J. H.: Secondary organic aerosol. 2. Thermodynamic model for gas/particle partitioning of molecular constituents, J. Geophys. Res., 107(D17), 4333, doi:10.1029/2001JD000542, 2002.

Reilly, P. J. and Wood, R. H.: The prediction of the properties of mixed electrolytes from measurements on common ion mixtures, J. Phys. Chem., 73, 4292-4297, 1969.

Robinson, A. L., Donahue, N. M., Shrivastava, M. K., Weitkamp, E. A., Sage, A. M., Grieshop, A. P., Lane, T. E., Pierce, J. R., and Pandis, S. N.: Rethinking organic aerosols: semivolatile emissions and photochemical aging, Science, 315, 1259-1262, 2007.

Robinson, R. A. and Stokes, R. H.: Electrolyte Solutions, London, Butterworths, 1965.

Salcedo, D.: Equilibrium phase diagrams of aqueous mixtures of malonic acid and sulphate/ammonium salts, J. Phys. Chem. A, 110, 12 158-12 165, 2006.

Seinfeld, J. H. and Pandis, S.: Atmospheric Chemistry and Physics: from Air Pollution to Climate Change, 2nd Edn., New York, Wiley, 2006.

Stokes, R. H. and Robinson, R. A.: Interactions in aqueous nonelectrolyte solutions: I. Solute-solvent equilibria, J. Phys. Chem., 70, 2126-2130, 1966.
Tang, I. N.: Thermodynamic and optical properties of mixed salt aerosols of atmospheric importance, J. Geophys. Res., 102, 1883-1893, 1997.

Wexler, A. S. and Clegg, S. L.: Atmospheric aerosol models for systems including the ions $\mathrm{H}^{+}, \mathrm{NH}_{4}^{+}, \mathrm{Na}^{+}, \mathrm{SO}_{4}^{2-}$, $\mathrm{NO}_{3}^{-}, \mathrm{Cl}^{-}, \mathrm{Br}^{-}$, and $\mathrm{H}_{2} \mathrm{O}$, J. Geophys. Res., 107, 4207, doi:10.1029/2001JD000451, 2002.

Wexler, A. S. and Seinfeld, J. H.: Second generation inorganic aerosol model, Atmos. Environ., 25A, 2731-2748, 1991.

Ying, Q., Fraser, M., Griffin, R. J., Chen, J., and Kleeman, M. J.: Verification of a source-oriented externally mixed air quality model during a severe photochemical smog, Atmos. Environ., 41, 1521-1538, 2007.

Ying, Q. and Kleeman, M. J.: Source contributions to the regional distribution of secondary particulate matter in California, Atmos. Environ., 40, 736-752, 2007.

Yu, J., Cocker III, D. R., Griffin, R. J., Flagan, R. C., Seinfeld, J. H.: Gas-phase oxidation of monoterpenes: gaseous and particulate products, J. Atmos. Chem., 34, 207-258, 1999.

Yu, S., Bhave, P. V., Dennis, R. L., and Mathur, R.: Variations of Primary and Secondary Organic Aerosols over the Continental United States: Observation-based estimates and model evaluation, Environ. Sci. Technol., 41, 4690-4697, 2007.

Zhang, Y., Seigneur, C., Seinfeld, J. H., Jacobson, M., Clegg, S. L., and Binkowski, F. S.: A comparative review of inorganic aerosol thermodynamic equilibrium modules: similarities, differences, and their likely causes, Atmos. Env., 34, 117-137, 2000. 